\title{
USER-INITIATED DESIGN FOR DISABLED CHILDREN: TEACHING AND LEARNING IN ONLINE DIY/MAKER COMMUNITIES
}

by

Ben Le, Hons. B.Sc., University of Toronto, 2014

\author{
An MRP \\ presented to Ryerson University \\ in partial fulfillment of the \\ requirements for the degree of \\ Master of Arts \\ in the Program of \\ Early Childhood Studies
}

Toronto, Ontario, Canada, 2016

(C) Ben Le, 2016 


\section{AUTHOR'S DECLARATION FOR ELECTRONIC SUBMISSION OF A MRP}

I hereby declare that I am the sole author of this MRP. This is a true copy of the MRP, including any required final revisions.

I authorize Ryerson University to lend this MRP to other institutions or individuals for the purpose of scholarly research.

I further authorize Ryerson University to reproduce this MRP by photocopying or by other means, in total or in part, at the request of other institutions or individuals for the purpose of scholarly research.

I understand that my MRP may be made electronically available to the public. 


\author{
ABSTRACT \\ User-Initiated Design for Disabled Children: \\ Teaching and Learning in Online DIY/Maker Communities \\ Master of Arts, 2016 \\ Ben Le \\ Program of Early Childhood Studies, \\ Ryerson University
}

A disabled child who requires an assistive device, like a wheelchair or prosthetics, often waits many months to use very expensive commercial devices that are less than ideal. However, as the popularity of DIY (Do-It-Yourself) Maker online communities increases, disabled children and their caregivers can instead take design back into their own control, by engaging in userinitiated design (UID). By learning from other DIY/Makers and their design tutorials, disabled children and their caregivers can custom make assistive devices at a fraction of the cost. What remains to be addressed are the barriers that prevent them from participating in these online communities; preliminary research has identified some barriers, including poor tutorial design and lack of perceived skill. Thus the purpose of this research paper was to further analyze popular online communities in order to make recommendation on how to increase disabled participation, further enabling them to practice UID. 


\section{ACKNOWLEDGEMENTS}

I would like to acknowledge my supervisor, Dr. Jason Nolan, who has been more patient and helpful than he realizes. I would not have been able to complete an MRP at all if you did not agree to supervise me so late in the semester. 


\section{TABLE OF CONTENTS}

Author's Declaration $\quad$ ii

Abstract $\quad$ iii

Acknowledgements $\quad$ iv

Table of Contents $\quad$ V

List of Figures $\quad$ vi

Chapter 1: Introduction and Background of the Researcher $\quad$ Page 1

$\begin{array}{ll}\text { Chapter 2: Purpose } & \text { Page } 5\end{array}$

$\begin{array}{ll}\text { Chapter 3: Literature Review } & \text { Page } 7\end{array}$

$\begin{array}{ll}\text { Chapter 4: Methods } & \text { Page } 35\end{array}$

$\begin{array}{ll}\text { Chapter 5: Findings } & \text { Page } 38\end{array}$

$\begin{array}{ll}\text { Chapter 6: Discussion and Implications } & \text { Page } 47\end{array}$

$\begin{array}{ll}\text { References } & \text { Page } 56\end{array}$ 


\section{LIST OF FIGURES}

Figure 1. Homepage of Craftster $\quad$ Page 38

$\begin{array}{lr}\text { Figure 2. Part of the City Guides Section } & \text { Page } 39\end{array}$

Figure 3. Sample of a Craftster Tutorial and Forum Organization Page 39

Figure 4. Tutorials for Learning Basic Skills in Crocheting $\quad$ Page 40

Figure 5. The Help Section of Craftster $\quad$ Page 40

Figure 6. The Homepage of Instructables, with a Partial List of Categories $\quad$ Page 41

Figure 7. Sample of an Instructables Tutorial $\quad$ Page 42

Figure 8. The Tutorials on how to Use Instructables, from Instructables. $\quad$ Page 43

Figure 9. A Portion of the Forum Section of Instructables $\quad$ Page 44

Figure 10. Homepage for Thingiverse $\quad$ Page 44

Figure 11. Thingiverse List of Resources for 3-D Printing Page 45 


\section{CHAPTER 1. INTRODUCTION}

\section{Overview of Research Paper}

The following research paper will begin with an introduction into why DIY/Maker online communities are sites of frequent user-initiated design (UID), and how this can benefit people with disabilities by placing the focus of design on the disabled peoples themselves. Following this, definitions of some key terms, leading then a brief literature review of critical disability studies and how it supports UID, followed by a literature review of the how design and disability intersected and lead to the conception of UID. This then brings us to how members of DIY/Makers online communities, like Instructables and Thingiverse, are practicing UID on a regular basis when users create and share their own designs in the shape of tutorials. This will finally lead us to our research questions of how to better UID by improving the quality of tutorials and the improving the quality of the DIY/Maker online communities. By analyzing three popular DIY/Maker websites for features that support UID, some recommendations for how to improve the DIY/Maker communities to maximize UID will be suggested.

\section{DIY Making and User-Initiated Design: Including Disabled People in Design}

With the advancements in technology and the online resources available to the general public, more people are using the Internet to learn and create, from cardboard furniture to rudimentary cellphones (Dalton, Desjardins, \& Wakkary, 2014). Websites like Instructables and Thingiverse offer numerous tutorials on how to create products people would have to otherwise purchase. Furthermore, these websites encourage the formation of online communities through free sharing and modification of those tutorials among users, contributing to what is known as DIY (Do-It-Yourself) Maker Culture (Lindter, 2014). Websites that cater to DIY/Maker Culture allows individuals to easily spread ideas that can benefit a much wider audience. 
An additional benefit in allowing consumers to design and create their own products is the potential for customizability and modifiability, both in function and aesthetics (Renda, Jackson, Kuys, \& Whitfield, 2015). This is of specific importance when considering children with special needs, as the capability of creating a product, that has the user's input—in this case a disabled child — guiding the entire design process opens up the possibility for increased accessibility and inclusion. This personalized type of design, or UID, is directly tailored to the individual, allowing for a better fit to the specific needs and circumstances that affect that individual.

Additionally, by having the consumers build these products themselves, they can drastically reduce the cost when compared to the retail cost of purchasing commercial products (Labb \& Neely, 2014). This is important as the high cost of assistive devices and technology, such as hearing aids and wheelchairs are already a huge barrier to access for many individuals (Borg \& Ostergen, 2015). The ability to build an assistive device tailored fit to the disabled individual, and to do so at a greatly reduced cost, could greatly benefit the disabled population. One example is the use of 3-D printing technology to design and produce customized prosthetics and other assistive technology (Buehler et al., 2015). Thus, as the popularity and proliferation of these DIY/Maker websites increase, it is important to evaluate their actual efficacy and see how they can be improved to best teach and distribute new ideas and useful products for people with disabilities.

Previous research from the design literature has examined past and current technologies, with most designers ignoring the usability for the actual consumer (Norman, 2002); unsurprisingly these new DIY/Maker websites face similar design challenges. Though there are a number of useful ways to pass on instructions, such as videos, text, imagery, etc., it is often 
difficult to determine methods actually work the best for which products. Research from the design literature has specifically looked at what makes a usable product and what common mistakes designers make, but there has not been much research on these DIY/Maker websites. This is unfortunate as their potential for widespread dissemination and inclusion of children with disabilities, may be hampered by poor design. The rise in popularity of DIY/Maker online communities is not just an additional avenue for people to create and build, but also an opportunity for inclusion for those who were previously excluded or disenfranchised (i.e. disabled people and/or their caregivers) with the current mode of design.

By having the users, especially those with specific product requirements as a result of disability, become the initial starting point in the design process, accessibility and inclusion becomes the focus in the creation of consumer products. As Goodley (2013) states, "disability is the space from which to think though a host of political, theoretical and practical issues that are relevant to all" (p. 632). Applying a critical disability lens to the design process can shed light on a normally quite exclusionary design practice and subsequently "illuminate emancipatory potential” (Goodley \& Runswick-Cole, 2013). DIY/Maker online communities can help make UID more mainstream and change what we consider normal design practices, but they must be carefully crafted in order to be as useful to those members of society that have been excluded from the design process.

\section{Background of the Researcher}

As someone who does not identify as a disabled person, or as a designer or DIY/Maker, I recognize that my graduate student understanding of either community is limited to the work and knowledge of those who do originate from or conduct research with those communities. However, this also places me as the typical novice beginning my entry into the DIY/Maker 
community, allowing me to see how the average user may interact or struggle with the current status of DIY/Maker online communities. Furthermore with the intention of increasing the focus on UID, I attempt to place myself in a position similar to that of an actual vested stakeholder, such as a parent, friend, or professional who may interact and care for people with disabilities. 


\section{CHAPTER 2. PURPOSE}

The end goal of this research paper is to suggest recommendations on how UID can be successfully implemented via a DIY/Maker online community. This was mainly motivated by the work of Belluci, Di Santo, and Nolan (2016), conducted at orphanages in Bolivia. Their study examined their process of designing a low cost and modifiable communication device for disabled children. By seeking the input from the children in the orphanages on how to modify the device to suit their own unique needs, Belluci et al. (2016) sought to ensure that these devices would be completely modifiable and maximally useful to these disabled children. While the process of conducting UID is very helpful in empowering people with disabilities to take charge of the design process, the traditional systems of designing, instructing, and building do not lend itself to this type of open-ended and modifiable design.

As a result, the question of what components or features can be taken from the existing DIY/Maker online communities and refined or enhanced to enhance UID, remains to be answered. By using the literature on design and disability to examine the current DIY/Maker websites, recommendations for determining what a user-initiated DIY/Maker online community/website requires will be presented. The eventual goal of these recommendations would be to implement them as a real changes to a DIY/Maker online community, which would allows disabled users to design their own equipment and devices, or request the assistance of online collaborators. This would help ensure that the user's interest is the focus throughout the design process. Furthermore, the design could then be further modified by other users with disabilities, while maintaining the usability in terms of instructions as well as the original credit for the original designers. The importance of a critical disability theoretical framework underpinning this model is important enough to stress once more; this model of how to best 
implement a DIY/Maker online community is not to design tools to make changes in people's lives, but instead to design tools to help people (disabled or otherwise) make changes in their own lives. 


\section{CHAPTER 3. LITERATURE REVIEW}

\section{Definitions}

There are some key terms and concepts that need to be unpacked, before getting into the literature review of the critical disability and design literatures. These terms will be used throughout the research paper, so it is important to have a clear understanding of them.

\section{DIY/Maker Culture}

DIY/Maker Culture revolves around the empowerment of typically non-professional designers to gain control over the process of design, making it a more open-ended and collaborative practice (Wakkary et al., 2015). Part of this entails the destabilization of traditionally one-way design practices, in which the designer creates a product with little to no input from the actual intended users (Wakkary et al., 2015). By instead supporting the notion that anyone and everyone has the ability to create and design, especially when there is platform for peer-to-peer communication and learning, more and more people are engaging in the creation and design process. Certain DIY/Maker websites like Instructables and Thingiverse offer users lessons on how to create their own custom products, while fostering online communities of amateur designers who are both interested in creating and learning from one another.

Furthermore, because DIY/Makers are typically testing out the designs on themselves/the person they are creating for, their speed at which they can release the design for use by others is extremely fast (O'Kane, 2016). This is of immense significance for those creating assistive devices, as Buehler et al. (2015) discussed, where many DIY/Makers have created an assortment of devices to assist disabled people, such as modified cutlery and 3-D printed prosthetic limbs. The ability to have a global social network when it comes to ideas around 
design and experimentation, while having the product itself implemented and tested at a local and individual level, allows for a great number of ideas and people to work on fine-tuning a generic product for their own needs (Nolan, 2016).

\section{User-initiated design}

User-initiated design (UID) is a relatively new term, going beyond the previous benchmarks in inclusive design, such as human-centered design and user-centered design (Giacomin, 2014; Nolan, 2016). While similar in attempt to shift considerations of the design of products towards users rather than designers, human-centered and user-centered design still inevitably revolved around the designer's understanding and goals, rather than the user's understanding and goals (Nolan, 2016). As stated by Nolan (2016):

User-initiated design represents an approach to design that relocates the traditional location of power, situated as the purview of the professional designer, into a dynamic interplay between the global sharing of design ideas and the local production and customization of those designs by/for the person with special needs. Through this shift and the interplay, the initiation of the design starts with the individual, through a process of close observation into the lived experience of individuals, how they challenge the normalizing pressures of their typical day-to-day cultural experiences, and how they envision their own needs, goals and desires being improved through a design intervention. Though of course some people with disabilities may not be able to undertake this critical reflection of their lives themselves, or can do it only with support, due to age, cognitive challenges or whatever limitation might get in the way, the locus of the design action primarily rests with them. (Introduction)

This type of design places the actual consumer's goals and interests before the designers, 
allowing the technical expertise of the designer to support the needs and requirements of the user. Sarmiento-Pelayo (2015) found that many disabled people engage in some sort of partial and informal UID while living in a world of products and spaces that are not suitable for them. However when disabled non-professional designers engage in this type of design, it is not often considered a valid way to conduct design. Sarmineto-Pelayo (2015) argues that mainstream designers should recognize UID as a useful design practice, specifically because the people who would provide the best information for design of these products should have the most input. UID recognizes that people with disabilities have lived, and thus most relevant, understanding and experience of the problems they face. UID, "which unite[s] experts and users in the experience of participation in the processes of design, [is] emancipatory" for people with disabilities "because they restore their power to create and recreate the environment" (Sarmiento-Pelayo, 2015, p.153). The user and their needs are first and foremost in this design process.

\section{Disability}

Goodley (2013) defines disability as the "structural, economic, and cultural exclusion of people with sensory, physical and cognitive impairments" (p. 631). It is important to note the difference between the biological-based impairment, and the experience of disability as a result of having an impairment living in world not designed for varied abilities. Some examples of impairments include being blind or deaf, developmental conditions like Down syndrome or cerebral palsy, and having decreased mobility due to trauma or disease (Robutaille, 2010). Throughout the paper, the writer will be using the terms "disabled people" and "people with disabilities" interchangeably, as neither term are universally accepted due to differing views on the relationship between disability and self-identity (Reaume, 2014). Some groups reject this 
label completely; an example of this would be some members of the Deaf community, who consider themselves part of a distinct cultural and linguistic minority group, rather than a disabled one (Reaume, 2014).

\section{Overview of Critical Disability Studies}

Gaining prominence in the 1980s disability studies sought to explore and examine the factors that lead to the exclusion of people with disabilities (Goodley, 2013). Prior conceptions

of disability were based on the medical-model, which strictly viewed disability as an individual, tragic, deficit that focused solely on the biological impairment (Davidson, 2016). Disability studies researchers sought to instead explore the societal factors that prevented people with disabilities from entering the workforce and thus unable to flourish socio-economically; disability was no longer an individual issue but society's problem (Thomas, 2007).

\section{Physical Accessibility}

A major early success of the disability studies movement was the narrowing in on physical barriers to inclusion for disabled people (Persson, Ahman, Yngling, \& Gulliksen, 2015). Being unable to work creates financial hardships, but being unable to enter buildings or homes or unable to carry out one's day-to-day tasks as a result of barriers or lack of support is much more encompassing. The emphasis on making spaces and buildings more amenable to people with physical disabilities is still important today, as researchers and policy makers try to ensure that homes and buildings are being built accessibly (Al-Zoabi, 2001; Andrade \& Ely, 2012; Malloy, 2008). This is of special significance because as Malloy (2008) notes, it is both in line with the UN Convention on the Rights of Persons with Disabilities as well as federal law, in this case the American with Disabilities Act (ADA) in the USA. Furthermore, as Davidson (2016) argues, disability is something that most, if not all, people will eventually face 
as a result of age. Whether this presents as mobility issues due to arthritis or cognitive decline due to diseases like Alzheimer's, we are all connected to or will face some form of impairment in our lives.

However, the inaccessibility of public buildings and spaces is just one point of exclusion for people with disabilities. Many designers also recognized the importance of designing products that allowed people with disabilities to assist themselves in living independently as possible, leading to designers focusing on making assistive technology such as screen readers, wheelchairs, electric scooters, (Robitaille, 2010). The accessibility of consumer products is another avenue of exclusion that is still being researched to this day, from cutlery, to clothes, and healthcare technology (Allsop, Holt, Gallager, Levesley, \& Bhakta, 2010; Herriott, 2015; Renda et al., 2015). Designers recognized that their products were not always usable by disabled people, and thus began designing products specifically for their use (Persson et al., 2015). Further information on the types of design that have evolved in recognition of the exclusion of disabled people will be discussed later on.

\section{The Experience of Disability}

This, however, was not enough and researchers began to draw attention to how the marginalization of disabled people moved beyond the physical alone (Reaume, 2014). An interest in fixing society's inaccessibility to those people with disabilities led to some advancements, like the modifications of building to make them more physically accessible, however later researchers began to question the theoretical absence of the body and the wide ranged lived experiences of people living with disability (Davidson, 2016). It is one thing to make spaces and products more accessible, and something else completely to change attitudes 
and societal practices regarding disabled people. The actual understanding and representation of disability is one that should always be carefully examined and re-examined.

An understanding of disability has to include the societal factors that foster exclusion, as well as the actual biological impairment factors that are part of the disabled persons lived experience. Moving back and forth between disability as solely a biological and medical problem to disability as a socially constructed and contextualized problem, researchers now seek to draw on how the two conceptions of disability actually interact; disability as the nexus between the lived experience of the biological body and the society and culture that body is influenced and categorized by (Reaume, 2014). What is typically agreed upon by different disability researchers is that including disabled people in the discourse, as both experts in their own lived experience and the advocates for their own advancement, are absolutely essential (Goodley \& Runswick-Cole, 2013; Reaume, 2014); understanding that the oppression of disabled people is best explained by those facing it in the first place, and that their impairments are a part of the disability experience and are just as important to examine as the societal factors.

Furthermore, part of this process involves breaking down the notion of a normative body and the binary of disabled and abled. This is where the critical aspect of disability studies really begins to take effect; as Goodley (2013) states "the word 'critical' denotes a sense of selfappraisal; re-assessing where we have come from, where we are at and where we might be going” (p. 632). Building on the works of queer, feminist, critical race, and Marxist theorists, critical disability studies also considers how disability interacts with other forms of oppression (Goodley, 2013). For example, in Renda et al.'s (2015) study examining how the use of assistive cutlery impacts viewer perceptions, it was found that the use of cutlery specifically 
designed for disabled people lowered perceptions of attractiveness, but only for women. Disability interacts with other forms of oppression like sexism to have vastly different effects on the oppressed person. This normative ideal is not unique to disability studies, and can be found in concepts from queer theory and critical race theory; the idealized person is heterosexual, male, white, and able-bodied (Campbell, 2009). However, since these normative ideals are only visible when they are being performed, their assumed position as the only correct human attributes is vulnerable to critique by performances of non-normativity (Davidson, 2016; Donaldson, 2013; Donaldson \& Runswick-Cole, 2013).

As Shildrick (2009) argues, the presentation and performance of the disabled body as a non-normative body both highlights and challenges the conception of what makes a normal body. By challenging the notion and definition of a normal body, it also challenged the types of social practices that we attribute with a normal body. In this case, "impaired embodiment demands new, inclusive and potentially exciting forms of response from others" (Goodley, 2013, p. 635), more specifically by changing the de facto design and production process. This emphasis on the disabled body as a non-normative body, which challenges the normative and mainstream conceptions of an able body, leads us away from the "disabled body as lack," and instead towards the "possibility... in which impaired bodies demand imaginative responses" (Goodley \& Runswick-Cole, 2013, p. 5). Changing the notion that products are just inaccessible to certain disabled individuals, and instead to the notion that the design process of consumer products is simply one that assumes a false standard of person, disabled or otherwise, is an example of one new possibility. The imaginative response to a design process that excludes a part of the population is to change the mainstream design process. Instead of reacting to buildings and products that are not accessible or inclusive, it would be better if the design was 
always considerate of the varying abilities of the human population and was thus amenable to modification and individualization.

\section{The Intersection of Design and Disability}

As designers recognized the problematic nature of design that had little to no input from the intended users, especially when these designs very effectively excluded people with disabilities, it became apparent that their design practices had to become more accessible. In different parts of the world and in different periods of time, many terms and concepts were developed that sought to rectify this situation. As Persson et al. (2015) found, terms like universal design, accessible design, design for all, inclusive design, etc. which all were working towards a common goal of meeting accessibility needs. The range of terms varies in their emphasis on accessibility, but in terms of actual user input, they are insufficient when compared to UID.

For example, the term universal design, which has been used interchangeably with design for all (Stephandis, 2001), as defined by Ronald Mace, is "the design of products and environments to be usable by all people, to the greatest extent possible, without need for adaptation or specialized design" (as cited in Persson et al., 2015, p. 508). A clear problem arises with this definition: how can a designer predict and accommodate for the entire range of abilities and requirements of the entire population? Especially with the explicit prohibition of adaptation or specialized design, which is clearly of value when considering something like prosthetics or other assistive device. While some principles of universal design, similar to other accessibility minded design concepts, are nonetheless important when designing products, such 
as "equitable use, flexibility in use, tolerance for error," (Persson et al., 2015, p. 508) the continued absence of actual input from the disabled population is still problematic. Later forms of design, namely user-centered design and cooperative or participatory design, sought to actively include the end-user in the design process at different stages and with different levels of actual inclusion (Sarmiento-Pelayo, 2015).

User-centered design, a concept developed by Donald Norman in the 1980s, recognized the folly in creating products without considering the actual consumer's subjective experience (Nolan, 2016). This type of design finally brought the end-user's input into the design process, and not just as an assessment of the product after design and production has already been completed (Mallin \& de Carvalho, 2015). This style of thought was "meant to be a challenge to the assumptions, attitudes, and power structure of what was then touted to be the most inclusive notion of design," (Nolan, 2016, UI Design section, para. 2) namely universal design's continued exclusion of the end-user. What may be the most crucial tenet of user-centered design, which Norman later renamed human-centered design, is that design had to put "human needs, capabilities, and behavior first, then desig[n] to accommodate those needs, capabilities, and ways of behaving" (Norman, 2013, p. 8). Taken even further, "the natural focus of the questions, insights and activities lives with the people for whom the product, system or service is intended, rather than in the designer's personal creative process or within the material and technological substrates of the artefact" (Giacomin, 2015, p. 610). It is made explicit that the designer's personal goals for the design, and even the possibilities of the materials itself, are second to the intended users.

In order to unearth and prioritize the end-user's goals and requirements, user/human centered design depends on a process that Norman (2013) calls the "iterative cycle," or "spiral 
method," of "observation, idea generation (ideation), prototyping, and testing" (p. 222). The term spiral method is actually more explanatory of the continuous increase in progress as a result of the iterative, or repetitive, cycle of stages (Norman, 2013). Each stage of the cycle is crucial in getting to a design that is closest to what the user really needs. Observations of the users in their day-to-day lives, which demonstrate how they interact with objects and spaces, what hinders and supports them in their environments, all before actually designing anything. After gathering enough observations, idea generation occurs, where the designer can then begin drafting designs while thinking creatively and critically with the observations. Finally prototyping and testing of the preliminary designs can take place, allowing for further observations and the spiral of progression then continues (Norman, 2013).

All put together, the repetition of the four stages paints a clearer picture on how the design needs to be modified further. This demonstrated a dramatic shift, where "the designer modified the design to the needs of the user, or at least some users, rather than expecting the users to modify themselves to the needs of the designed object" (Nolan, 2016, UI Design section, para. 2). User/human-centered design is significantly more inclusive of the user in the design process than previous types of design, and definitely has components that should still be utilized when conducting UID. There are however, some important differences between the two types of design.

For user/human-centered design, as much as observing users and having them test the prototypes provides direct user input, the designer is still the person in charge. Additionally the impetus for the product being designed in the first place is still coming from the designer. Finally, the completed product is still meant for large-scale production and distribution, as the end goal is "to produce a great product, one that is successful, and that the customers love" 
(Norman, 2013, p. 36). To be successful here, meaning selling well and bringing in a profit for the company. This also perpetuates the notion of a one size fits all mentality that continues from universal design (Nolan, 2016). When examining the actual testing phase of user/humancentered design, Nielsen (2000) suggests that only three tests, with 5 unique users per test, is necessary to properly test a product for usability. That translates to 15 people being used to represent a huge portion, if not the entirety, of the population. It is understandable that the financial and/or time constraints of a company trying to sell a product leads to limits on testing, but this demonstrates how the problem of universal design has been reduced, but not eliminated.

UID, by its definition and implementation, whole-heartedly rejects the one size fits all mentality still commonplace today. Designers utilizing UID are not looking to sell a product for the masses; they are instead trying to improve and support and individual person (Nolan, 2016). The disabled person, if possible, should be the main designer for their assistive devices. Thus the implementation of an online DIY/maker community for UID is an attempt to highlight the importance of changing the current design process by recognizing the unique embodied experience of the disabled person as an opportunity of new possibility. Making UID more mainstream tackles disability from the societal practice end, and the highly individualized capability of UID recognizes the unique circumstance of each disabled person.

What remains to be explored is how best to go about implementing an online platform that best fosters UID, both in usability of the website and features required to ensure the user and/or their representatives are truly driving the design. However, due to the relatively new nature of UID, at least how it has been described above, there is little explicit research on this 
type of design. However, when examining the DIY/Maker literature, as explored below, it appears that DIY/Makers are actively engaged in UID practices.

\section{DIY/Maker Overview}

Traditional conceptions of design and production elicit images of large corporations and assembly lines, where one single design on an item can be mass-produced at extremely high rates, with little to no input from the intended consumers of the product (Mota, 2014). However, a designer and a company decide to create a product, the consumer or user has to accept this product as is or simply not use the product. This is what Mota (2014) calls the "broadcast approach" (p. 6) to design, and it is an extremely unidirectional and normative in form. Other researchers call this the "design for the market," (Margolin \& Margolin, 2002, p. $24)$, and the primary concern is to create products that cater to a majority of the population and thus sell the most units. Unfortunately, this means that certain minority demographics, like disabled populations, are not considered as viable consumers (Margolin \& Margolin, 2002).

In comparison, the "distributed approach" (Mota, 2014, p. 8) to design is a newer form of design that encourages public participation. This approach "blurs the distinction between producers and users and views each user as a potential co-creator” (Mota, 2014, p. 9). Although the originating idea may reside within typical institutions like companies and academia, by offering their designs to the public, or by releasing programmable open-source hardware, these organizations invite more public input on design (Mota, 2014). While it began with digital information and software, by the mid-2000s it expanded with programmable open-source hardware and personal fabrication tools, leading to the gradual development of the DIY/Maker movement. 
Furthermore, the presence and centrality of these traditional design institutions are becoming less and less important, as more individuals and companies come together to create their own "hackerspaces" (Williams, Gibb, \& Weekly, 2012, p. 18). These hackerspaces, or maker spaces, are places where individuals can come together and pool resources in order to jointly buy technology and machinery that assists them in their DIY endeavours, that would otherwise have been too expensive for one person to afford (Williams et al., 2012). Furthermore, these hackerspaces are hubs of learning and teaching, where novice DIY/Makers can take classes or workshops and learn from/with other DIY/Makers (Williams at al., 2012). One example is TechShop, a DIY/Maker community that has several locations across the United States and charges a membership fee so that DIY designers have access to technology like laser cutters, 3-D printers, and welding equipment (Stangler \& Maxwell, 2012). Magazines, workshops, and entire festivals are now dedicated to the DIY/Maker Culture, and the popularity of this movement is only increasing (Stangler \& Maxwell, 2012). The DIY/Maker movement has found a home in China as well, in contradiction to the notion that China is "Silicon Valley's unimaginative counterpart," where "Silicon Valley comes up with the ideas and China manufactures them" (Lindtner, 2014, p. 150). Chinese DIY/Makers, hopefully soon to be housed by 100 government-sanctioned hackerspaces, are seeking to change the common label of “'made in China' to 'created in China"' (Lindtner, 2014, p. 150).

\section{DIY Products}

It is clear that for many people all over the world, the DIY/Maker movement is one of empowerment and a radical change from the hegemonic design and manufacturing process. Whether working with computer codes, 3-D printers, wood, or cardboard, the sheer creative potential of the DIY/Maker movement is simply astronomical. The types of products that 
DIY/Makers have been designing and creating includes, but is not limited to: furniture, decorative items, toys, and assistive technology (Mota, 2014). While some DIY/Makers may be designing simply for art or hobby, many others are also designing to meet specific functional needs. For example, O'Kane (2016) reported on a burgeoning group of diabetic DIY/Makers who are customizing glucose monitors and insulin pumps to have features that even the newest commercial versions do not have. Walsh, Roberts, Morris, and Heinemann (2015) advocated for the development of more advanced glucose monitors that can send data to smartphones or personal computers, similar to wearable fitness trackers like the Fitbit or the Nike+ FuelBand, but they appealed to large telecommunication companies. Following the broadcast approach to design, they believed that only large companies would have the money and resources to develop and test these complicated technological devices for diabetes management.

Instead, O'Kane (2016) found that some diabetic DIY/Makers were not waiting for large technology companies to release a commercial app, and instead were creating their own glucose meters with the ability to upload blood glucose data to the cloud, which has the added bonus of allowing parents to remotely track their diabetic children's blood sugar levels. Other individuals are combining the insulin pump with the glucose monitor to create a self-controlled artificial pancreas (Hurley, 2014), which is something researchers believe is the next step in diabetes management (Walsh et al., 2015), but not yet commercially available. However, one major potential problem with the designs of such life-altering devices being made public is the risk of users without adequate technical expertise attempting to copy the design and causing someone major harm (Hurley, 2014). It is apparent that for the most advanced type of products that have life-saving functions need to be carefully designed and built to ensure safety, which the average DIY/Maker may not have. 
Luckily for certain DIY technological items that are being produced, lack of technical expertise does not normally have such serious and life-threatening ramifications, but may prove to be less useful to the user if designed poorly. Researchers have examined how the DIY/Maker community can be specifically used for designing assistive technology (Buehler et al., 2015; Hook, Verbaan, Wright, \& Olivier, 2013; Hook, Verbaan, Durrant, Olivier, \& Wright, 2014). While these products may not be as curative as the development of an artificial pancreas, they are still extremely useful and valuable to the disabled population. For someone with a disability, having a hearing aid, a mobility device, or a prosthetic limb could help them live life more comfortably, safely, and easily.

However, if the product does not meet their individual requirements, then that person is more likely to abandon their device; according to Phillips and Zhao (1993), close to $30 \%$ of assistive devices are abandoned within the first 5 years of use. One might assume that the rate of abandonment would decrease with time as technology and products get better and more advanced, but more recent research shows essentially the same, if not worse, abandonment rates; $30 \%$ of assistive devices are abandoned within the first year of use (Federici \& Borsci, 2014). To compound this, children who require assistive technology may also outgrow their initial sets of devices and their parents are thus required to purchase new devices very frequently, leading to an extremely high financial burden (Hook et al., 2014). When compared to other electronic devices like mobile phones, which are more luxury devices than assistive, they averagely last upwards of 2 years in countries like Canada and the USA, whereas countries like Brazil and Mexico have an average mobile phone life of around 4 years before abandonment (Entner, 2011). This is troubling when you consider that mobile phones are much 
more readily accessible, yet not as necessarily crucial for the daily living of someone with a disability.

Further hindering the ability to obtain an assistive device is the confusing and timeconsuming process of obtaining the device in the first place, involving referrals and assessments from multiple organizations (Copley \& Ziviani, 2004). Add in the fact that many of these assistive devices are so high-use that they break down often and must be sent in for repairs or replacement (Hook et al., 2014), and the person in need may spend more time waiting for the device than is reasonable.

As a result, parents of children with disabilities, friends and loved ones of people with disabilities, and disabled people themselves are joining the DIY/Maker movement, to find a better way of creating and designing assistive devices. In Buehler et al.'s (2015) study, they examined the use of Thingiverse, an online DIY/Maker community specifically geared towards utilizing a commercial 3-D printer called MakerBot, and they looked at how and why people were crafting customized assistive devices. Products ranged from pillboxes, splints, prosthetics, accessories for existing assistive devices, and tactile media (Buehler et al., 2015). Overall the designers ranged from graduate students, family members of people with disabilities, disabled people themselves, and simply hobbyists, further emphasizing the widespread appeal of the DIY/Maker movement.

What was truly interesting in their study was the discovery of the motivations for why people were engaging in DIY for assistive technology. While some designers interviewed indicated that they were simply experimenting with 3-D printing or completing a project for university, more than half were trying to fix some sort of problem they or someone they knew were facing (Buehler et al., 2015). They did not wish to wait for a product to be invented for 
them, nor did they want a device that may have been ill suited for the specific needs of the disabled person. Furthermore, for those designers that were creating assistive devices like prosthetic limbs, they managed to create custom-fit devices for "hundreds of dollars instead of in the thousands" (Buehler et al., 2015, p. 528).

These findings echo what Hurst and Tobias (2011) found when examining other DIY/Makers designing custom assistive technology. One case study examined a DIY/Maker named Tom Jeary, who has been creating customized assistive technology for over 40 years. Jeary uploads his designs for free on a website he maintains, and generally refuses payment for any devices he creates. When interviewed by Hurst and Tobias (2011), they found that " $[\mathrm{w}] \mathrm{ith}$ few exceptions, anything that Jeary builds for others is at no cost. He buys all materials at his own expense and perceives it to be just like any other hobby related cost" (p. 14). Jeary is trying to better the lives of disabled people by creating customized assistive devices, at a fraction of their commercial cost, and at no cost the user themselves. While not explicitly mentioned in the studies themselves, these instances of DIY making above are clear examples of UID.

\section{What Does a User-initiated DIY Maker Online Community Require?}

The burgeoning research examining DIY/Maker online communities, while relatively new, has examined the types of DIY products being created, barriers to users/their caregivers from engaging in DIY making, and the efficacy of different types of DIY instruction (Behler et al., 2015; Dalton et al., 2014; Hook et al., 2013; Hook et al., 2014; Hurst \& Kane, 2013; Tseng \& Resnick, 2014; Wakkary et al., 2015). By examining what the research has found thus far in terms of strengths and common problems of these websites, some preliminary criteria for what an idealized user-initiated DIY/Maker online community should contain, can be formed. Taking this further, considerations brought up by the critical disability literature, a full set of criteria 
can be created. Then, using this set of criteria to evaluate popular DIY/Maker online communities, a complete model that takes the best components of the existing websites and combines them with novel features or processes can be created.

\section{Barriers to Entering and Thriving in a DIY/Maker Online Community}

Part of implementing a successful online community is ensuring that people are comfortable joining, making, and contributing to the community. As Williamson et al. (2015) argued, the best way to decrease the time it takes to get assistive devices to disabled people, while also decreasing the rate of abandonment, is to increase public involvement in the design of assistive technology. One possible way to increase public participation is to open the design doors to the general public, over the Internet via a DIY/Maker online community. However, there are some interconnected factors that can prevent users from joining and/or actively participating in the community.

Hook et al.'s (2014) study examined how caregivers and professionals involved with children requiring assistive devices (i.e. parents, Occupational Therapists, medical physics practitioners that crafted prosthetics, teachers from schools for disabled children, etc.) utilized DIY making to create custom assistive devices. Some of the main concerns brought up by their participants was lack of confidence in skills to make and design, lack of time available to invest in DIY making, and lack of safety of the DIY devices (Hook et al., 2014). These three main concerns are all somewhat related, as lack of skills can only be rectified with taking the time to learn these DIY making skills, after which the amateur designer is likely still at a higher risk of creating products that are not safe.

Similarly, O’Kane (2016) found that lack of technical expertise was the number one reason that prevented users from actually attempting a novel artificial pancreas design; there 
were over 14,000 members in the Facebook group, but less than 3500 had actually downloaded the design, which in itself is not indicative that the design was actually built. A related factor, as previously mentioned, pertains to the safety of the device itself; just as Hurley (2014) found that parents were themselves concerned with the increased risk of DIY diabetes management devices, Hook et al., (2014) also found that the healthcare professionals had concerns that DIY assistive devices were not as safe. An example included a wheelchair ramp being built without side rails or an anti-slip surface, something that "a professional with appropriate experience and training would have included" (Hook et al., 2014, p. 603).

In terms of the time investment to participate in DIY making, as Buehler et al. (2015) argued, emphasizing to users that the time and money saved by crafting custom built assistive devices, rather than waiting for a professionally made or off the shelf device, is significant. This process becomes even faster as "rapid prototyping tools" (Hurst \& Kane, 2013, p. 636), like 3D printers and laser cutters, become more accessible. Furthermore, the ability to have other more experienced users assist in learning skills, or with the actual design itself, can help speed up the making process for beginner DIY/Makers (Hook et al., 2013). However, many people may not be aware of these time savings, so increasing awareness of the benefits to engaging in DIY making is important as well. Overall, it is imperative that these concerns be addressed so that more people feel comfortable engaging with a DIY/Maker online community. Further possible solutions to the above issues will be discussed in a subsequent section. Now once DIY making reaches has established itself as an accomplishable task for novice or previously excluded populations, it is important that the DIY/Maker online communities themselves are as informative, user-friendly, and accessible as possible. 


\section{Problems with the Design of the DIY Tutorials}

One of the most important aspects of the DIY/Maker community is the ability to share designs and ideas with other people, and this is done through tutorials. As Dalton stated, "[t]utorials are central to the DIY culture: they are a place to share knowledge, learn from others, and exchange with the community though commenting and asking questions" (p. 1405). Tutorials can be found online in websites like Instructables and Thingiverse, and the range of products that users have created tutorials for is extremely large and varied. However, if the quality of the tutorials is poor, then it may have some detrimental impacts; people may be unable to make the product, people may see a confusing tutorial and forego any attempts at all, the ability to share and modify the design for specific users may be hindered. For the sake of aiding UID, the quality of these DIY/Maker tutorials should be high, in terms of clarity and openness for modification.

Considering that the DIY/Maker movement is relatively new phenomenon, the research specifically examining the design and usability of DIY/Maker tutorials is understandably even newer, with a majority of the literature emerging within the last 10 years (Buehler et al., 2015; Dalton et al., 2014; Hurst \& Kane, 2013; Kuznetsov \& Paulos, 2010; Tseng \& Resnick, 2014; Wakkary et al., 2015; West \& Kuk, 2016). Beginning with Wakkary et al.'s (2015) study, in which they examined several DIY/Maker tutorials from assorted DIY/Maker online and offline sources, including Instructables, Thingiverse, MIT Media Labs, and Make Magazine. Their team of researchers actually built the products from the assorted designs, in order to evaluate the strengths and weaknesses of their different tutorial formats. Their study is of specific importance for this research paper as they produced very clear criteria for what a good versus a bad DIY/Maker tutorial looks like. 
What should be stressed is that their equipment, access to materials, and competency and experience with DIY Making prior to the research study indicates that they are not novices in the DIY/Maker community (Wakkary et al., 2015). If a team of experienced and well-equipped DIY/Makers face difficulties in following the tutorials from these popular DIY/Maker sources, it can be safely assumed that true novices would face the same, if not greater, challenges if they attempted the same designs. Unsurprisingly, of the 10 design tutorials the researchers attempted to follow, they only managed to successfully build 8 products (Wakkary et al., 2015). While an $80 \%$ success rate is still good, it should be worrisome that when experienced makers are following step-by-step instructions, which are meant to be usable by anyone, they are still unable to successfully build all the products. They surmised a number of issues among the tutorials they evaluated, and while lack of accuracy of the tutorial was the general problem, this is further broken down into issues with: “1) competencies, components, and tools, 2) sequencing, 3) and communication" (Wakkary et al., 2015, p. 613).

Beginning with the issue of competency, many of the tutorials evaluated often assumed a certain skill level of the viewer, however "anticipating a level of expertise can be difficult and it is a challenge to assume what competencies constitute a level of expertise, especially since [the] DIY builds required a wide range of skills and knowledge from crafts to electronics. For example, a builder can have advanced electronics skills but little knowledge of physical construction" (Wakkary et al., 2015, p. 614). This presumption of skill manifested in the form of omitted tools, skipped steps, and even incomplete lists of components. The authors of the tutorials simply expected their viewers to fill in the gaps. This practice can also be seen as somewhat exclusionary to those who are new to the DIY/Maker movement, making it harder 
for new users or users who may already feel unable to contribute, like disabled people (Hurst \& Kane, 2013).

In regards to the components and tools, some tutorials chose to list them all at the beginning, and others chose to present the items within the steps of the tutorial. Both methods had positives effects; a list at the beginning makes it easier to prep the resources for the design prior to actually building, while having the requisite items presented at each step provides key reminders as to what is necessary at each step (Wakkary et al, 2015). Similarly to this, Dalton et al. (2014) attempted to convert two tutorials into a format inspired by cookbooks, where they had the list of required items presented in sequence, rather than all at the beginning. However, they had bolded the items as to make them stand out from the instructions, allowing users to still do a quick scan of the page and perceive a list, which allowed them to avoid repetition of text. Unfortunately, their emphasis on minimalism also meant very little visual material like pictures or videos were included. Tseng and Resnick (2014) also found that some tutorial authors described the formats of their instructions like "an edited recipe," (p. 426) with carefully curated images and text to be as simple and straightforward as possible. It is apparent that tutorials have to walk a fine line between overloading viewers with information and not providing enough detail.

The issue of sequencing pertains to the "completion of tasks within a tutorial in the right order," (Wakkary et al., 2015, p. 614). They found that some tutorials did a poor job of laying out the actual steps, with some tutorials having an exorbitant amount of information in one step, while other tutorials had sequences that failed to connect steps to one another in a logical fashion (Wakkary et al., 2015). What was also found to be an issue in sequencing, and related to the issue of assumed competency, was either omitting detailed instructions on how to 
complete difficult technical tasks or only including that information in an external tutorial or link. What is apparent for sequencing is that the steps have to be clear, simple, flow logically, and cover all the required steps within the tutorial or at the very least indicate at the beginning of the tutorial what specialized skills are required and where to learn them.

Finally, the issue with communication, or how a tutorial conveys the necessary information (i.e. with text, video, imagery, etc.) is centered on poor uses of media or lack thereof (Wakkary et al., 2015). They found that some tutorials are composed of predominately text, and only show photos of the completed product, which do not provide very much assistance with actual building, especially if the product is particularly spatially complicated. Furthermore, some tutorials that did utilize high-resolution photos sometimes led to additional confusion, such as unlabelled pictures out of sequence with the steps they were positioned adjacent to (i.e. showing an image of the intermediate product at step 7, but positioned next to the text of step 5). Similarly, Kuzentsov and Paulos (2010) found that although media-rich tutorials that contained instructional videos were the most helpful for readers, they were used the least by authors, likely because instructional videos "require a long time to edit," especially with the other possible additions of "descriptive overlays, voice annotation, interactive features," etc. (p. 303).

Fittingly, other researchers looking at the quality of DIY/Maker tutorials found similar problems to the above. Tutorial authors are not following a template, and have wildly varying formats, with some authors emphasizing conciseness and brevity, leaving "just enough process and context for people to replicate their design" (Tseng \& Resnick, 2014, p. 426). Other authors attempted to tell a full story of the design process, including any mistakes they themselves made in order to help other DIY/Makers avoid common problems, but this inevitably lead to 
lengthier tutorials (Tseng \& Resnick, 2014). When Tseng and Resnick (2014) examined the process in which DIY/Makers actually created and uploaded their tutorials to Intructables, they found that it was a generally very time consuming and complex process. This is similar to Kuznetsov and Paulos' (2010) study of assorted online DIY/Maker communities, where they found that the primary reason someone would not upload or share their design was due to the lack of time. However, thanks to the open-access of these designs, many users would combine tutorial instructions form multiple sources, add additional information, saving time from having to make up the steps from scratch (Tseng \& Resnick, 2014).

In summary, there are many areas of DIY/Maker tutorials that have been found to be problematic. Some tutorials assumed a certain skill level of the viewers, other were not consistent in how they presented the tools and materials needed, the step-by-step instructions for some of the tutorials had large gaps between steps or too much going on in one step, the media used to convey the instructions (i.e. images, video, text etc.) were not always used effectively. DIY/Maker tutorials from these online communities appear to have a lot of room for improvement. However, the researchers above did also find good tutorials, or at least good parts, and all put together, some preliminary criteria for a good DIY/Maker tutorial and website can be formed.

\section{The Criteria for a Good DIY/Maker Tutorial and Beyond}

The preliminary criteria that Wakkary et al. (2015) set up are by no means a detailed checklist of what to include in all future tutorials and DIY/Maker websites, but they certainly provide some key points that should always be considered when authoring a tutorial. Their recommendations include:

- Ensure information is accurate; 
- Do not omit necessary tools and components;

- Clearly identify necessary tools and components;

- Identify prerequisite and necessary competences;

- Clearly sequence tasks and required information;

- Divide tasks into manageable steps;

- Communicate through texts and images in proximity to each other and relevant tasks;

- Provide quality images with consistent orientation. (Wakkary et al., 2015, p. 615)

To build upon this set of criteria, Wakkary et al. (2015) argue that DIY/Maker tutorial authors should work together with, or at least take notes from, interaction designers. According to Karlgreen, Ramberg, and Artman (2016), interaction designers are concerned with the way humans interact with or between artifacts, in this case meaning websites and tutorials. Interaction designers attempt to make spaces and tools that improve human interaction and communication, and Wakkary et al. (2015) call for "better tutorial tools and tutorial generation tolls. These tools not only make it easier for authors to create and assemble content but foster better practices of tutorial authoring by the design of good tools" (p. 616).

It is the combined efforts of DIY/Makers and interaction designers, what Wakkary et al. (2015) calls "hybrid design," (p. 617) which aim to foster "the skills and knowledge to design with technology as a medium; the in-depth analytical focus on users of designated systems; and the trained ability to co-design and mediate designs with other experts" (p. 616). This hybrid design can positively influence DIY/Maker online communities, specifically by striving to improve both the "content and the form, or in DIY terms: instructions and the instructional media" (Wakkary et al., 2015, p. 617). What is especially important with the addition of interaction design considerations to DIY/Maker online communities is the recognition that you 
must be considerate of the intended audiences, as this has a profound impact on how you should alter the way in which users interact with the online community.

For instance, if the goal is to emphasize UID via features of a website, especially in the interest of the disabled population, there are certain components of the DIY/Maker online community that should be encouraged. One of the most important features that researchers have argued for, especially those that have examined the use of DIY making for assistive technology (Buehler et al., 2015; Hook et al., 2013; Hook et al., 2014; Hurst \& Kane, 2013; Hurst \& Tobias, 2011; O'Kane, 2016; O'Kane et al., 2016), is the increased participation and accessibility of DIY/Maker online communities. This can be achieved in multiple ways, one of which is improving the quality of the tutorials to maximize usability as mentioned above, however there are other website-oriented steps that can be taken to increase accessibility. Certain features that may already be included in some DIY/Maker online communities, but may need improvement or refinement, will now be explored.

One of the most important requirements of UID is the focus on the individual circumstance, and this is most prevalent in DIY/Maker online communities when designs undergo "personalizing and remixing” (Tseng \& Resnick, 2014, p. 428). Users will often utilize multiple designs and combine then and modify to suit their own needs, however it is not easy to suggest changes or to ask questions regarding improvements on other users' designs, other than leaving a comment (Tseng \& Resnick, 2014). However, they may instead post a new tutorial that gives attribution to the original tutorial designer. This helps to ensure that designs are open to be personalized while also giving due credit to the original tutorial author. DIY/Maker online communities should have a process for remixing or modifying other users designs embedded in the website, which can possibly improve on the collaborative effort by having a process in place 
for "materials substitution" or "process optimization" (Tseng \& Resnick, 2014, p.428). The personalization is taken further by encouraging and providing direct means for collaboration between more experienced or professional designers and novice designers.

Another issue that can be addressed at the website level, is the barrier to participation in the online community. Specifically, as previously mentioned, the issues of lack of skill and lack in device safety. Many researchers have suggested that the DIY/Maker online communities should aim to foster the cumulative learning of important skills necessary to participate, and encourage the design collaboration with those who are experts, either professionally or from personal experience (Kuznetsov \& Paulos, 2010; Hook et al., 2014; Hurst \& Kane, 2013; Hurst \& Tobias, 2011). Beyond just commenting on other user's tutorials and asking questions there, some possible solutions could include having specific tutorials that teach basic skills that progressively lead to more complicated designs, and if possible, have a request a design option embedded within these online communities (Hook et al., 2014). This is especially targeted at those who are experts and may wish to support new users, by having professionals crafting tutorials on the basic skills, offering advice on how to ensure safety of devices, and actually creating designs and/or prototype for users who need more technical assistance.

As an extension of this, it is important to build more accessible DIY/Making tools and technology. Hurst and Kane (2013) examined how to make DIY/Making more accessible, so they developed 2 different technologies, one that allowed for visually impaired designers to 3-D print visualizations of mathematical equations, and the other that allowed for easier 3-D modelling by taking multiple scans of real objects in order to create a digital model that could then be modified and exported in a file format ready for prototyping. These technologies are specifically meant for including those who may have felt or been excluded from engaging in 
DIY/Making with the typical tools and technology, such as people with disabilities and people with little to no previous DIY/Making experience (Hurst \& Kane, 2013). Ensuring that DIY/Maker online communities can work in conjunction with these more accessible tools would further include people with disabilities and their caregivers as primary designers.

In sum, some features of DIY/Making online communities that foster UID include: the open and free access to designs and tutorials, addressing the competency gap that prevents novice users from attempting to DIY/Make, and encouraging the collaboration between experienced DIY/Makers and newcomers (like disabled users) to the online community. With a more complete set of criteria that includes considerations for well-formed tutorials, with considerations for well-designed DIY/Maker online communities, we can begin our analysis of some popular DIY/Maker online communities. The above suggestions and criteria may already exist for some of these websites, and this is by no means the end of the line for improving DIY/Maker online communities, but it is a few steps in the right direction for centering the importance of UID. 


\section{CHAPTER 4: Methods}

This research paper sought to examine the current quality of DIY/Maker online communities, specifically in terms of tutorial strength, as well as evaluate their ability to foster

UID. While the content and details of tutorials are dependent on the individual authors creating them, the DIY/Maker online communities set the parameters for features and requirements of the tutorials. In order to examine if DIY/Maker online communities have the features that are in support of UID, a content analysis of 3 DIY/Maker online communities: Instructables, Thingiverse, and Craftster was done. According to Kalof, Dan, and Dietz (2008) content analysis (CA) is "a technique used to analyse texts, whether written, spoken or visual," and common "[t]ypes of communication or texts that have been analysed include magazines, videos, personal diaries, advertisements, poetry, government documents, recorded conversations and speeches" (p. 105).

While the application of content analysis to websites and web content is relatively new, researchers have used content analysis to analyze a range of Internet texts including personal home pages, blogs, and Wikipedia (Bates \& Lu, 1997; Kim \& Kuljis, 2012; Pfeil, Zaphiris, \& Ang, 2006). However, traditional requirements of content analysis are not always applicable for web content and communications. As Herring (2010) argues, Web Content Analysis (WebCA) can be broken down into "image analysis, theme analysis, feature analysis," among other subcategories, and part of WebCA can include "classifying and counting phenomena of interest" (Herring, 2010, p. 245). WebCA uses the general principles from content analysis and combines them with methods from other disciplines, like discourse analysis, to "recast traditional CA notions such as comparable units of analysis, fixed coding schemes, and random sampling to fit the requirements of web research" (p. 244). This sentiment was similarly echoed 
by McMillan (2000), who argued that "[g]iven the magnitude and changing nature of sites, some creativity would seem to be needed in defining the context unit" (p. 87) of analysis. The differences between websites and the fluid status of content demand a more flexible and openended approach to web-based research.

Accordingly, these considerations affect the content analysis used in this research paper. The sampling is not random, but purposively chosen, as representative of a range of popular DIY online communities; Craftster is geared towards crafts like knitting and jewellery, Thingiverse is specifically targeted towards 3-D printing, and Instructables is a general DIY tutorial site with no explicit specified genre. They have different design focuses and different emphasises on materials and methods of DIY/Making. Furthermore, the focus of the content analysis will be features of these online communities that support UID, with the possibility of new features yet to be researched to be found in these online communities. An additional component of this analysis will then be the suggestion of new features from the literature, that have yet to be incorporated into these DIY online communities.

The following questions will be used to guide the analysis of the features present in the selected DIY/Maker online communities:

- Are there instructions on how to create a good tutorial?

- Is there a search function, a way of tagging designs, and/or a way of filtering designs by some sort of category of interest (i.e assistive devices or assistive technology)?

- Are there lessons or tutorials that assist new, or previously excluded, users with both basic skills to participate in DIY Making, and in using the website itself? 
- Does the online community support users in practicing user-initiated design? And how is it supported/encouraged (i.e can users learn, collaborate, and/or receive advice from other users to help themselves DIY/Make?)

- How is disability represented, or not represented, in these online communities?

How the three DIY/Maker online communities address these questions may vary, and multiple features may cover these general questions. By exploring these DIY/Maker online communities and observing what features are available and how users interact with each other and these features, some recommendations for furthering the emphasis of UID among these communities will be suggested. 


\section{CHAPTER 5: FINDINGS}

\section{Craftster}

Due to practical limitations, every single web page is not explored or inserted as a figure, but the main features of interest that pertain to DIY/Making or user-initiated design are presented. The website for Craftster can be found at www.craftster.org, and is dedicated to crafts such as knitting, sewing, cooking, visual arts, and more. Craftster is owned by Internet Brands, an American Internet media company (Ewaskiw, 2011). The homepage can be seen in

Figure 1, where the major sections of the website can be found. Beginning with the features

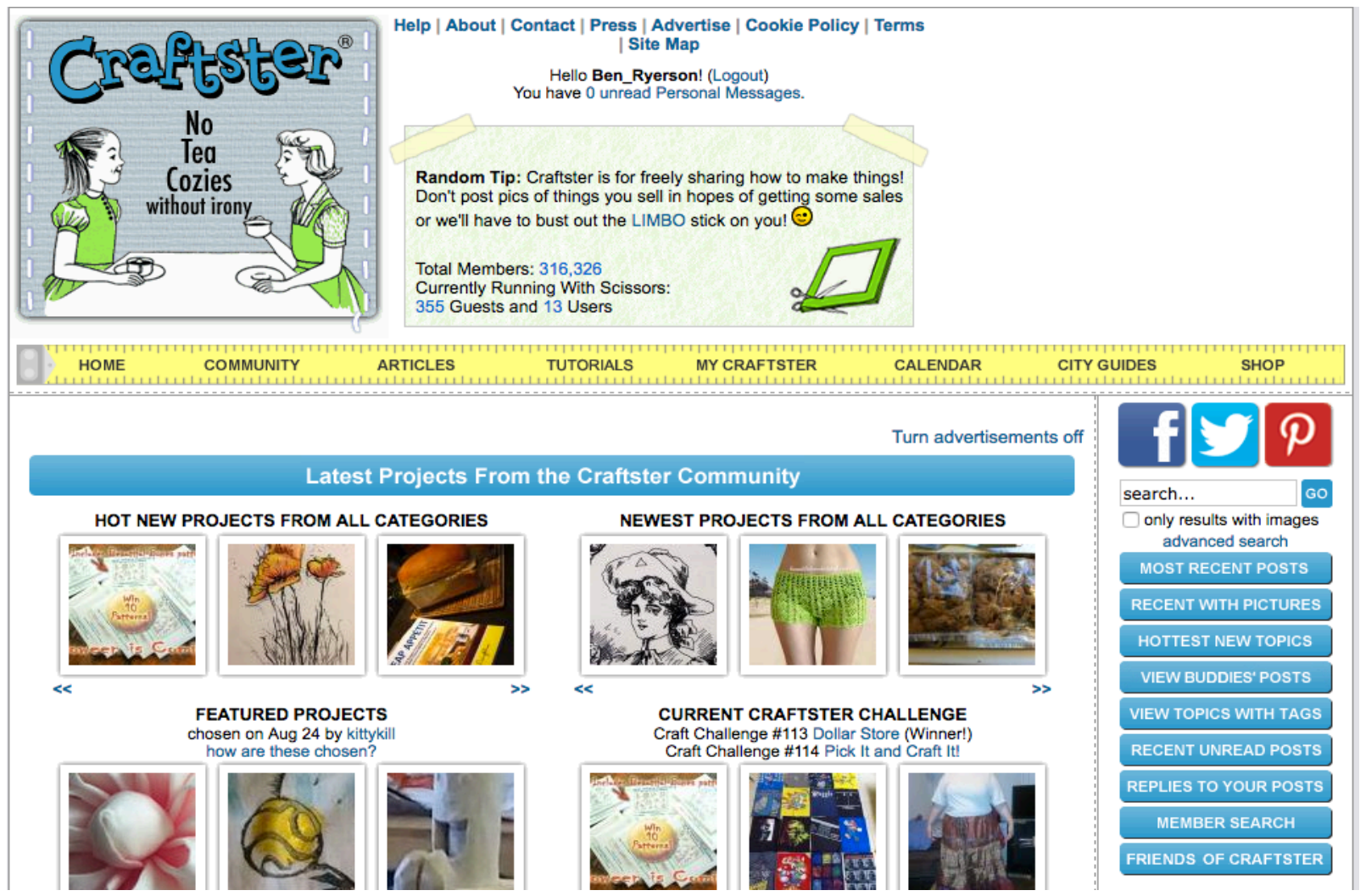

Figure 1. Homepage of Craftster. The different sections of the website can be seen (Craftster, n.d.a).

visible from the home page: users can register and create a profile, users can directly private message other users, users can search by product or tag, users can explore by craft (within the 
Community tab), or users can go straight to tutorials (Figure 1). The City Guides tab allows users to post more information about local information for crafting, like meet-ups with other users, festivals, and locations of crafting shops, etc. (Figure 2).

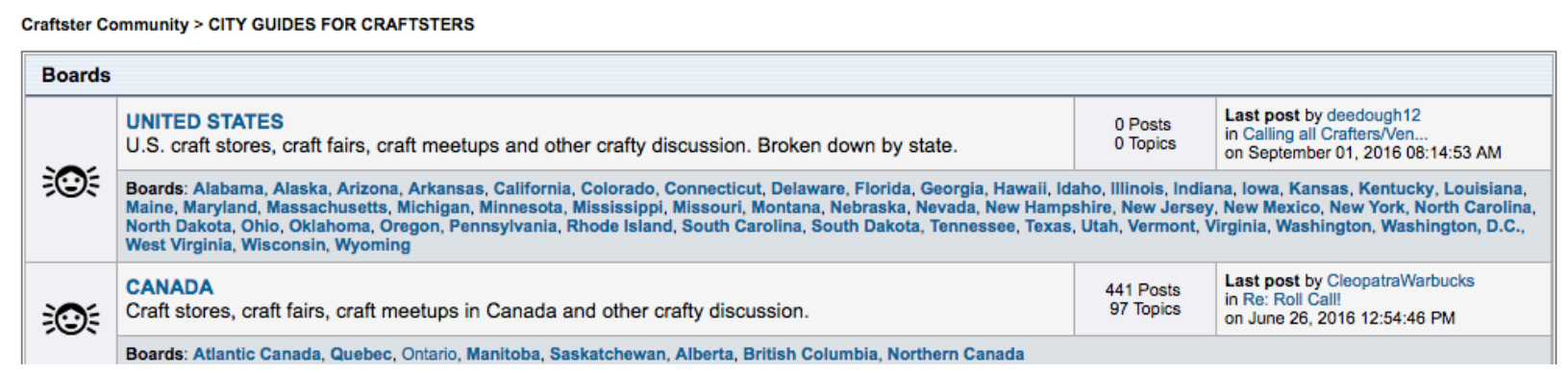

Figure 2. Part of the City Guides Section. Local events for crafting, like craft stores or festivals, are posted here (Craftster, n.d.-b).

The bulk of Craftster presents as a forum, with the different crafts split into communities, which are further split into different discussion boards, and subsequent threads as the main organizational system (Figure 3). Users can ask questions or post their designs by starting new threads within the community board. The tutorials themselves are regular text posts with embedded images, with formatting of the tutorial being left up to the user (Figure 3).

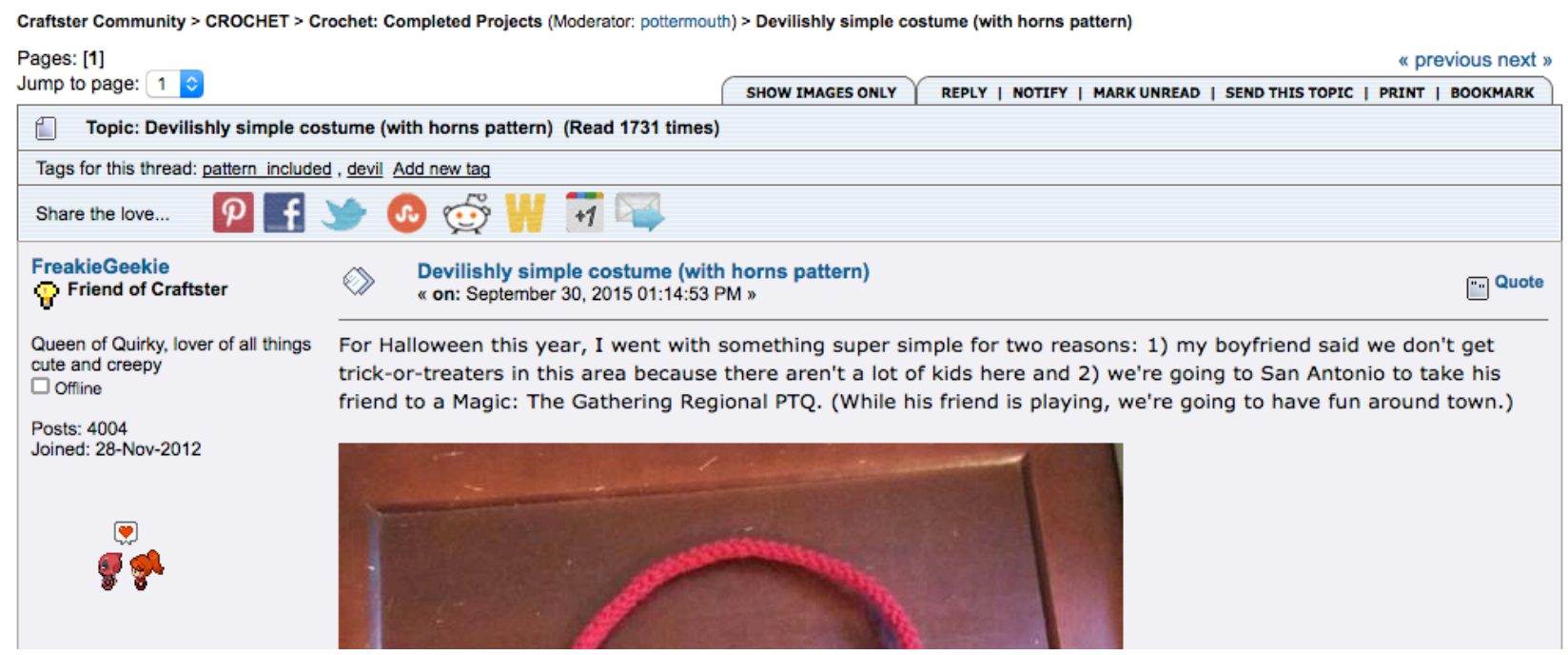

Figure 3. Sample of a Craftster Tutorial and Forum Organization. The tutorials are simply text posts with the required information. Craftster is organized into separate sections, or communities, that lead to further discussion boards and tutorial threads (FreakieGeekie, 2015). 
The majority of each community also has a section that has tutorials on learning basic skills for that specific craft (Figure 4).

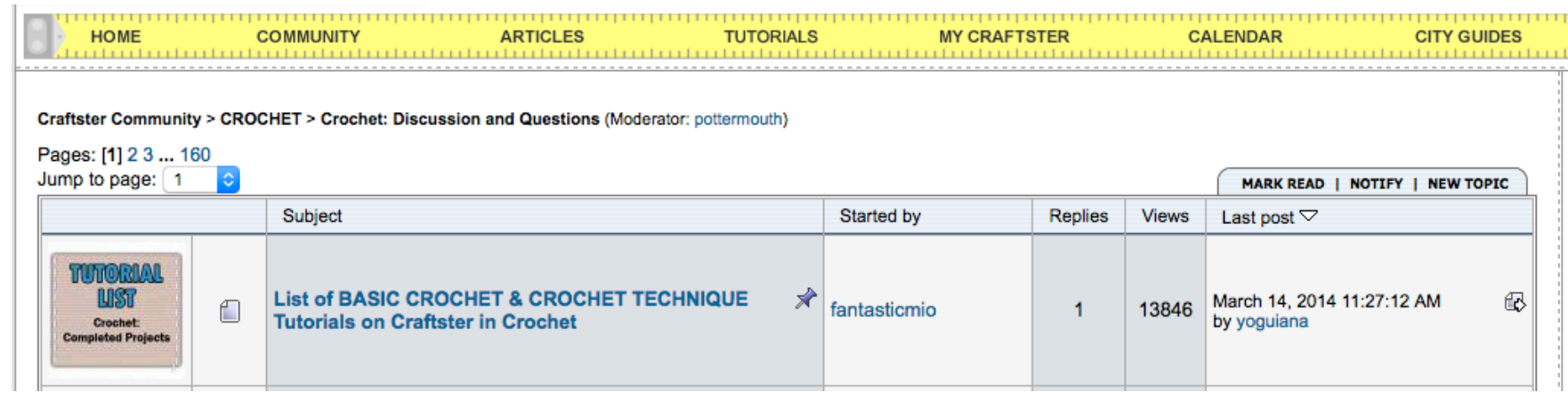

Figure 4. Tutorials for Learning Basic Skills in Crocheting. Certain communities had a section for beginners to learn the basic skills and required tools (Craftster, n.d.-c).

Finally, there is also a help section to help new users learn how to navigate, post, and contribute

to the community (Figure 5).

\section{The Craftster Need To Know Guide}
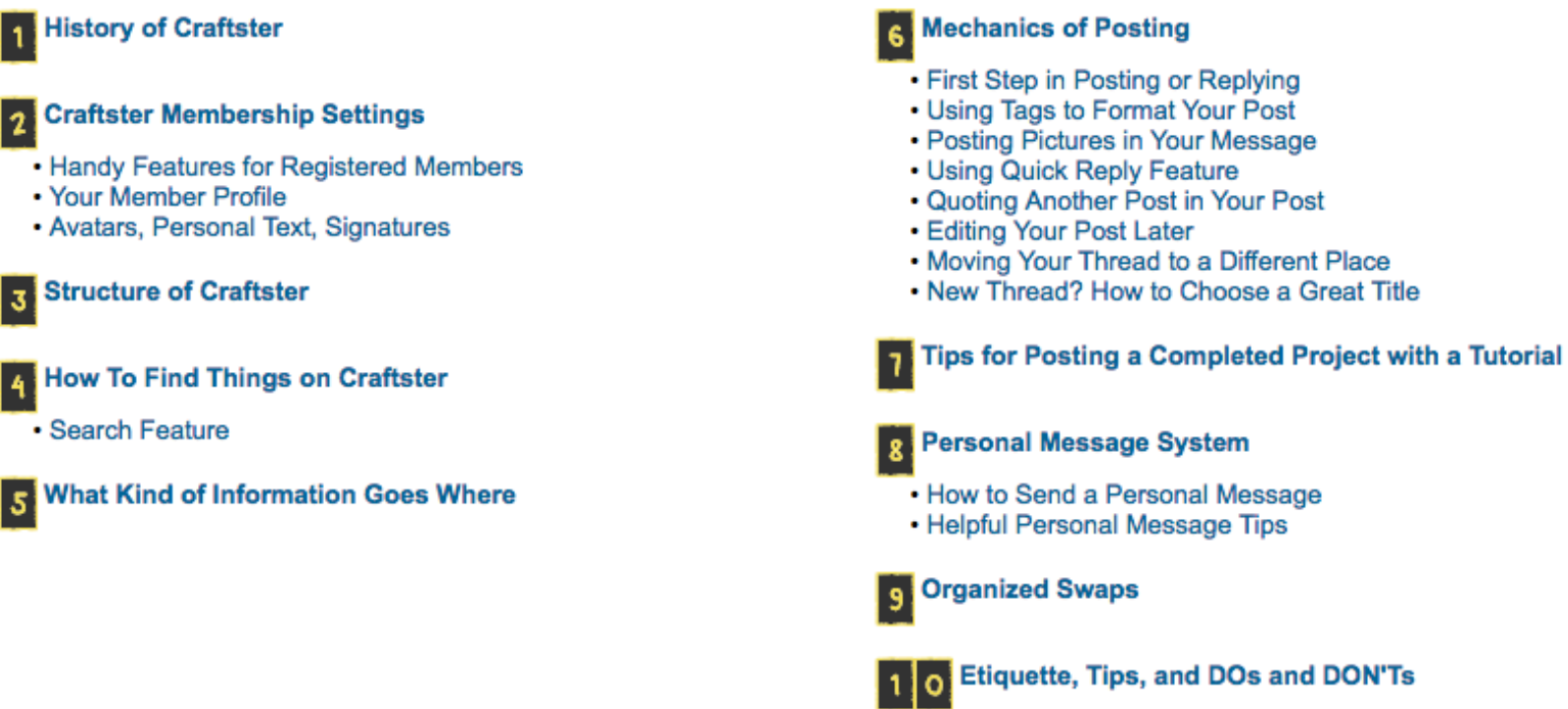

Figure 5. The Help Section of Craftster. Detailed information regarding the use of Craftster can be found here (Craftster, n.d.-d).

Overall, Craftster's layout and tutorial format leans towards a more casual DIY/Maker online community, with an emphasis on exact replication rather than individualized modification, as 
can be seen in knitting patterns, food recipes, and more. Furthermore Craftster users are not typically designing products that fulfill an assistive purpose.

\section{Instructables}

The website for Instructables can be found at www.instructables.com, and is owned by Autodesk, a multinational software corporation (Wauters, 2011). Instructables is a general DIY/Maker online community covering a wide range of products and fields, as indicated in

Figure 6.

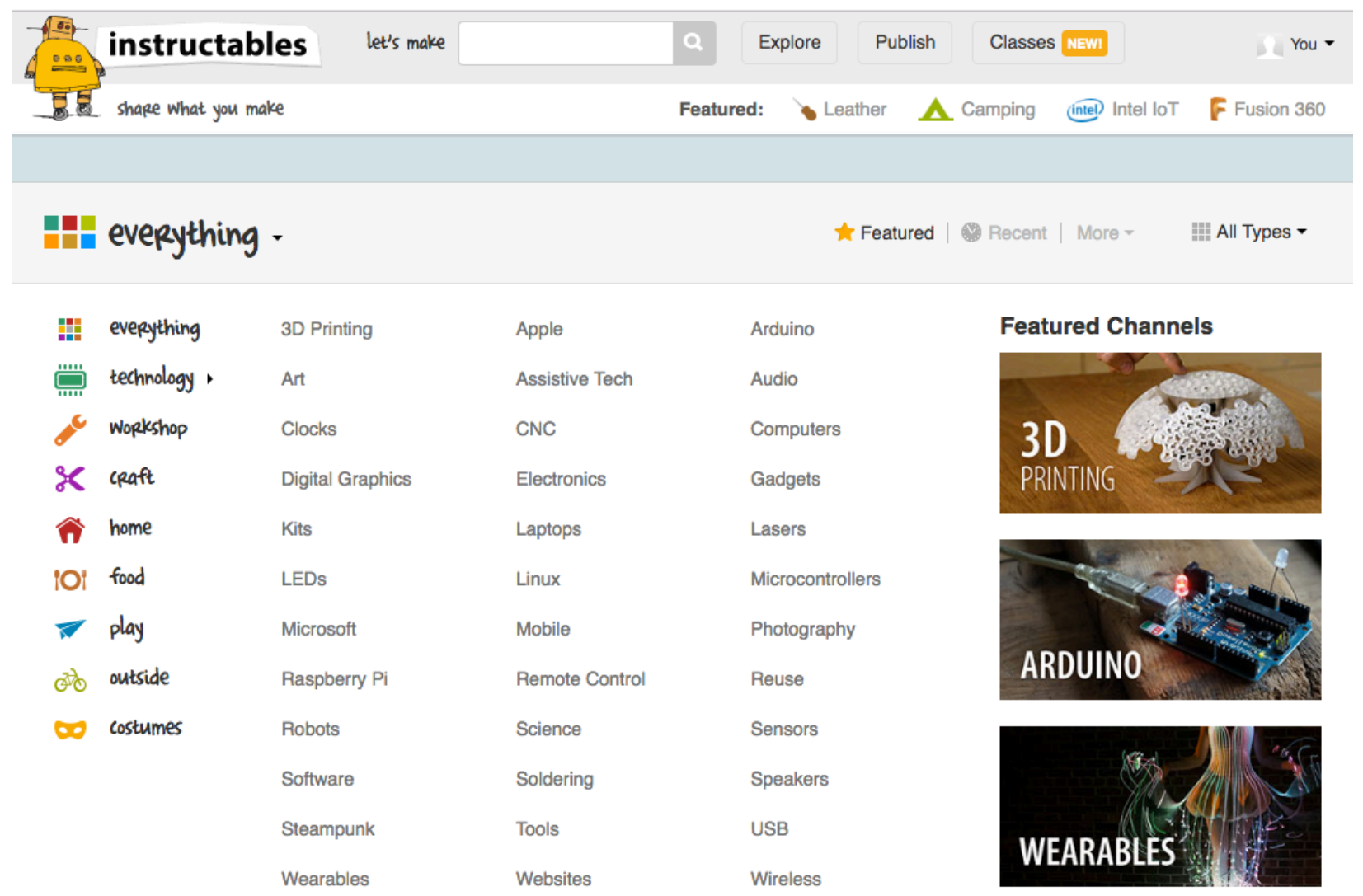

Figure 6. The Homepage of Instuctables, With a Partial List of Categories. Instructables covers general DIY making, so it has a multitude of product, material, and technological categories (Instructables, n.d.-a).

Instructables is very explicitly geared towards the tutorials, with the search bar providing results that link directly to tutorials. Some of the common features Instructables has include the ability to make a profile, to publish tutorials, and to search and view other tutorials (Figure 6). While 
Instructables is free to use, they have a paid premium account membership option which grants access to extra features, such as unlimited classes, which regular users would otherwise have to pay for (Figure 6), the ability to download tutorials in the form of a PDF file (Figure 7), and reduced advertising, among other features.

Within the tutorial page itself, there are ways of saving the tutorial to one's favourites, commenting on the tutorial, sharing the tutorial on social media, among other features (Figure 7).

\section{strong plastic samurai sword by mountaing}
进 Download \#\# 4 Steps
Collection
III) I Made it!
- Favorite
Aः Share -

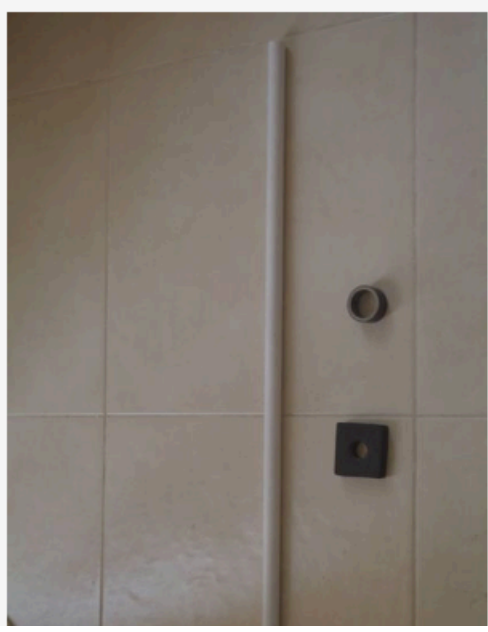

About This Instructable

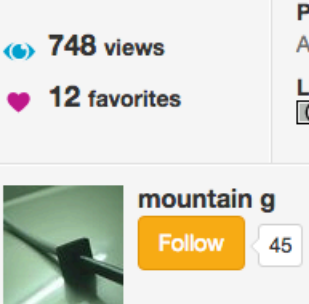

Bio: We are 2 active 14 year olds that have loads of fun and cool ideas. MAKE SURE YOU CHECK OUR STUFF OUT!! We will soon ... More $n$

More by mountain g:

Figure 7. Sample of an Instructables Tutorial. The tutorial layout include features like sharing the tutorial on social media, saving the tutorial to one's favourites, and commenting on the tutorial (mountain g, 2015).

The tutorials are composed of step-by-step textual instructions that typically have embedded images, and in some cases videos as well. If the tutorial has a 3-D printing component, the tutorial will normally have the 3-D file available for the user to download. Instructables incorporates many features specific for collaboration and modification of designs in the tutorial editor; this includes opening up the tutorial to specific users to become co-authors, as well as 
providing multiple types of creative common licences that restrict how new users may use, sell, or modify the created design (Figure 7).

Tutorials themselves are created with an embedded tutorial editor, which provides a framework for creating the tutorial, complete with tagging of key words connected to the tutorial, and input of images, text, and/or video. This allows for tutorials to follow a similar layout, regardless of author. Instructables also offers a tutorial on how to use the editor, as well as a tutorial on how to create a high quality tutorial (Figure 8).

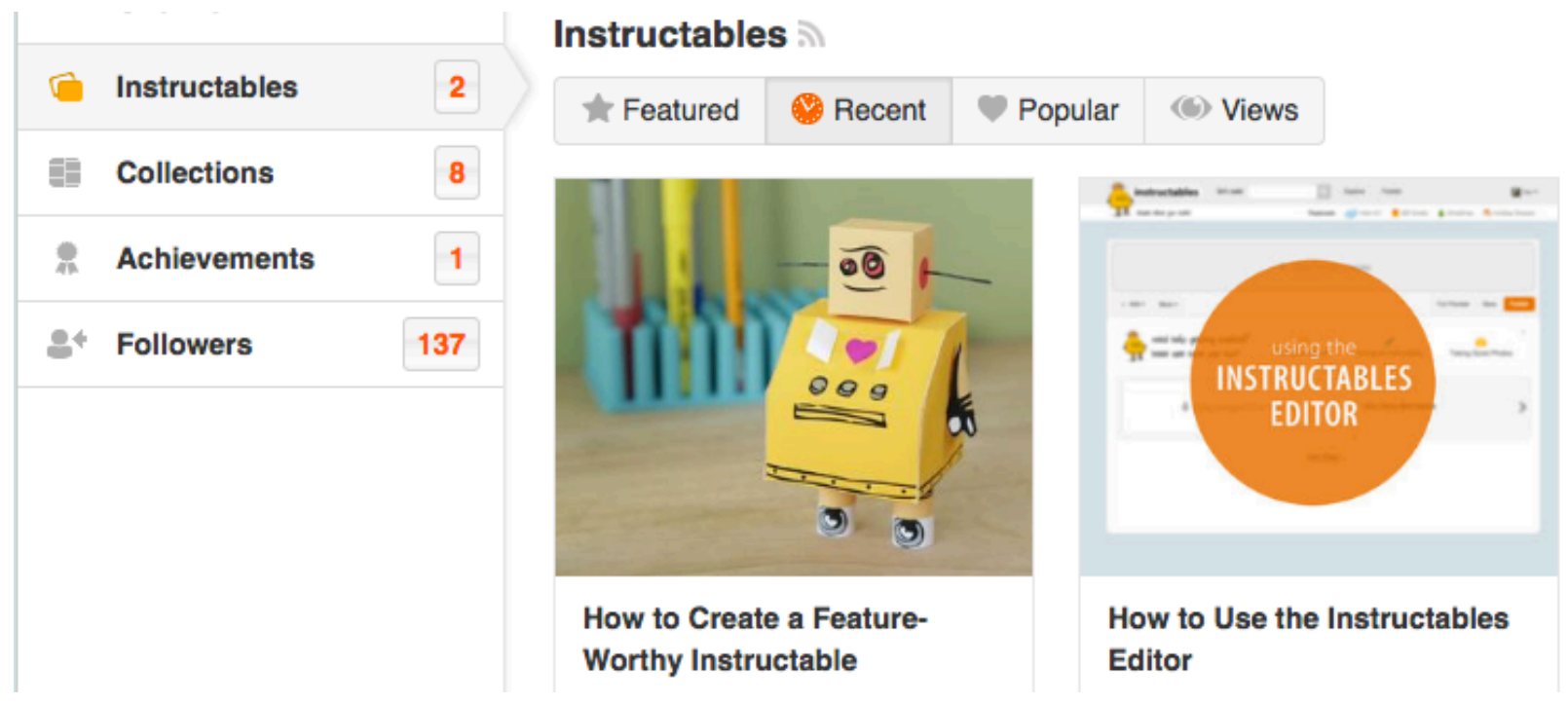

Figure 8. The Tutorials on how to Use Instructables, from Instructables. The two tutorials that Instructables offers on tutorial creation (instructables, 2015).

There is also a separate Forum section where additional information can be found about Instructables, as well as allows users to pose questions and seek the advice of other users. This Forum has similarly categories as the tutorials, with additional topics such as Frequently Asked Questions, requesting designs/products, and buying and selling designs/products (Figure 9). 
FORUMS (view all)

\section{Art}

All topics art related.

\section{Burning Questions}

Post an idea for an Instructable and somebody just might make it! posts replies

$788 \quad 10583$

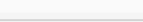

299524339
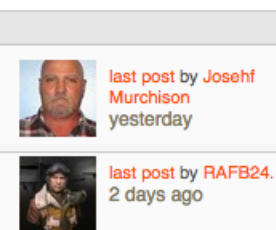

Figure 9. A Portion of the Forum Section of Instructables. The Forum is another avenue for users to communicate with one another, beyond commenting within the tutorials (Instructables, n.d.-b).

Lastly, Instructables has apps for mobile devices so designers can create and look at tutorials from their cell phones or tablets.

\section{Thingiverse}

The website for Thingiverse can be found at www.thingiverse.com, and this DIY/Maker online community is focused exclusively on 3-D printing. Thingiverse is owned by MakerBot, an American 3-D printer company (Overstreet, 2013).

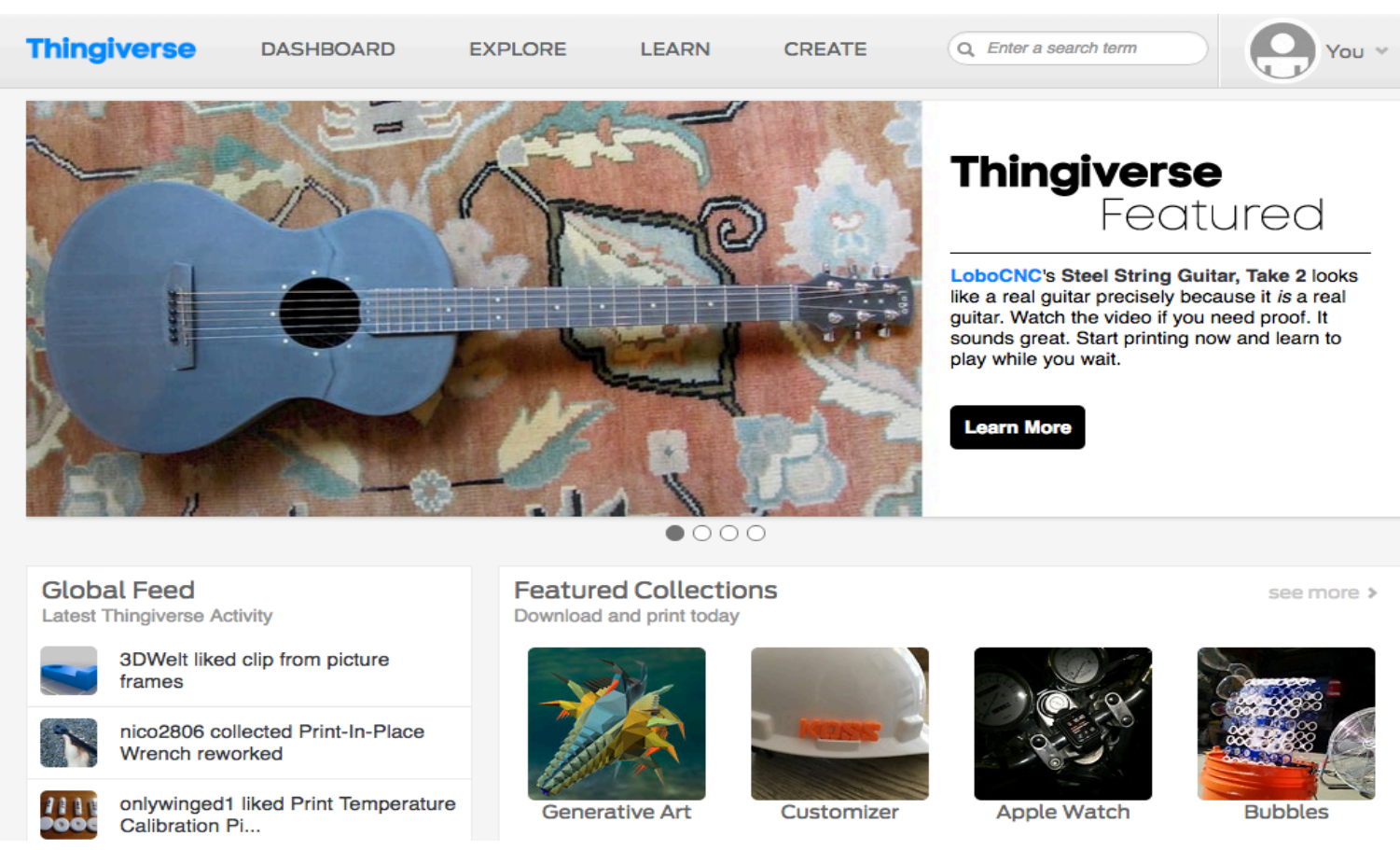

Figure 10. Homepage for Thingiverse. The homepage has the typical search feature and different sections of the website in the tabs (Thingiverse, 2016a). 
The website itself has some typical features, such as the ability to make a profile, to search for and view tutorials by product or tag, and to upload your own tutorials (Figure 10).

Under the Learn tab, there are multiple tutorials on how to actually use Thingiverse as well as several other free apps and programs for 3-D modelling (Figure 11).

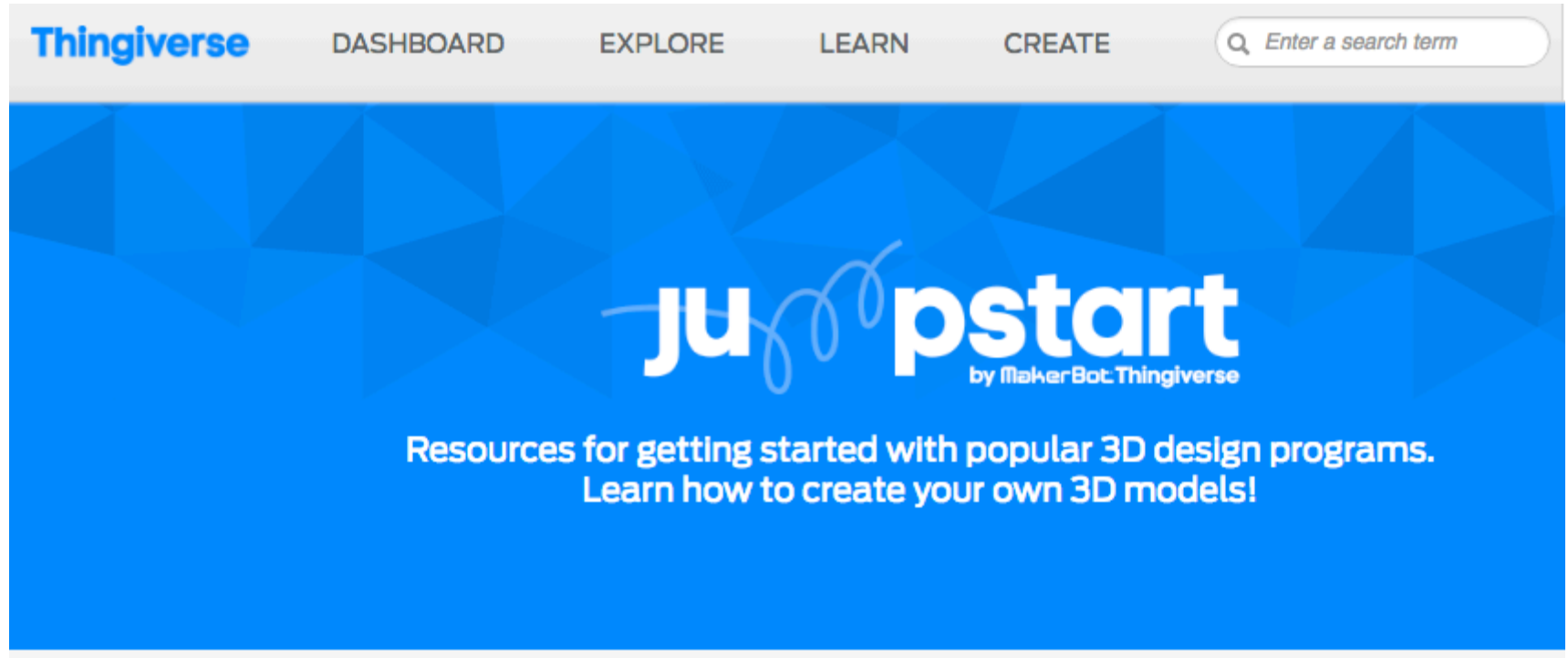
(T) Thingiverse
Difficulty: Easy Type: Customize, remix, and inspire
Platforms: Web, iOS, Android Cost: Free
Join the largest 3D printing design community and browse for 3D printable files that you can download, remix, and customize. Learn more,

\section{(P) PrintShop \\ Difficulty: Easy Type: Tap and drag \\ Platforms: iPad Cost: Free}

Figure 11. Thingiverse List of Resources for 3-D Printing. Thingiverse offers tutorials for many 3-D modelling and printing programs (Thingiverse, 2016b).

After searching for and finding a design of interest, users can immediately test out the digital design, as all tutorials have the 3-D design file available for download. In fact, some of the tutorials are modifiable within Thingiverse's web-based 3-D program, Customizer. 
The tutorial page itself includes the ability to favourite a tutorial, a comments section, images of the 3-D model as well as the actual printed product in use, text instructions, the tags used for the design, and the 3-D design files for download (Figure 12).

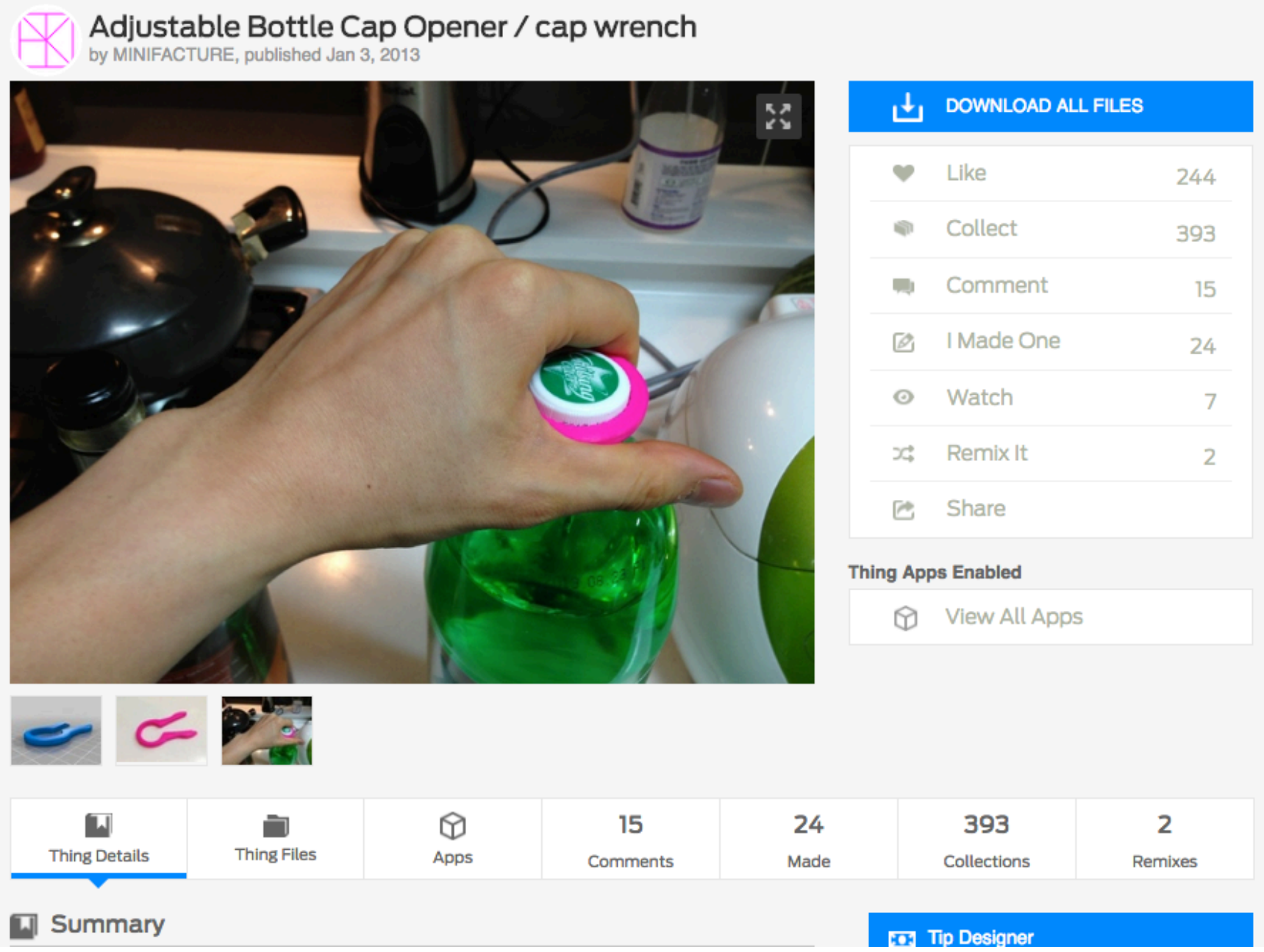

Figure 12. Sample Tutorial from Thingiverse. Typical features of the tutorial include images, the 3-D design files, and the text instructions (MINIFACTURE, 2013).

The Groups section of Thingiverse is where the forums are located, with users joining groups that pertain to a specific topic like engineering or Arduino. This is where users come together to ask questions and seek help, as well as post specific designs that match the topic. Some users will also use the groups to request a design. 


\section{CHAPTER 6: DISCUSSION AND IMPLICATIONS}

\section{General Features Supporting User-Initiated Design}

UID requires that the design focus is relocated to the end-users themselves, and where users share their designs for others to further use and modify for their own needs (Nolan, 2016). However it is not enough to simply have an online space that allows for UID, these communities should have features that support and encourage users of the websites to engage in UID. As mentioned above from the literature, some DIY/Maker online community features that encourages UID include: the ability to freely share and modify user-created designs with other users, information or tutorials to address competency gaps, and the ability/encouragement to get advice and have direct collaboration with other more experienced uses. Additionally, the presence or emphasis on UID to specifically assist people with disabilities may further encourage other disabled people to engage with the online community. Overall, the observed websites did contain these features to some degree, however certain websites do a better job of encouraging UID, which will be further analyzed below.

All three websites have open tutorials for an assortment of products, in a setting that encourages replication and modification. This essential characteristic of DIY/Maker online communities inherently encourages user-initiated design, by offering information and a template from which users can copy and/or experiment from. All three websites allow users to make profiles and encourages users to ask questions and add comments on one another's designs or in forums. This promotes learning and active contribution in the practice of DIY/Making among the users. Furthermore, these websites offer users instructions on how to use and contribute to the community, which helps to ease the transition for new users into DIY/Making. All three websites also provided some sort of information and/or tutorial on basic 
skills/tools needed for advanced making, although some were user-generated while others were implemented by the website creators themselves. Finally, the ability to receive advice or assistance on a design or product was common to all 3 websites, however the level of integration within product/tutorial design varied. Moving past the general features that most DIY/Maker online communities have, the community specific and especially helpful features will be explored below.

\section{Craftster}

Craftster was chosen because it represented what a casual DIY/Making online community, that emphasizes social interaction and showcasing of products. Casual here meaning the majority of the designs and products fulfilled artistic rather than overtly functional purposes, with crafts like knitting, paper crafts, and home décor. There is little to no disability presence or focus in Craftster, although that may be due to the types of products and designs. The focus is not to provide life-changing designs that serve an assistive purpose for people with disabilities, but rather for sharing art and meeting other crafty people. As a result, the forum style of the website emphasizes comments of praise over constructive comments or modifications to the design, as well as the showcasing of products, rather than informative tutorials.

The emphasis on social interaction, however, has the benefit of fostering the relationships between users. This is further made important by the City Guides feature, a unique feature to Craftster, in which the forum is divided in to geographic area and users can set up meet-ups or indicate when other crafting events or opportunities were in the local area. Taking the connection beyond a purely online one allows users to meet and network and perhaps develop collaborative partnerships, where the needs of the individual can be attended to in person and 
supported by the specialist or more experiences user. As argued by Hook et al. (2014) increasing collaboration between amateurs and experts can increase user participation in DIY/Making. Furthermore, being able to meet with more experienced users at local venues, with the express purpose of learning or demonstrating a certain craft or design, can further boost the skills and confidence of new users to DIY/Make and possibly encourage the modification of designs for themselves. This helps to bridge the competence gap, a priority brought up by Wakkary et al. (2015) for increasing user participation in DIY/Making. In addition, many of the specific crafts communities has a dedicated section on learning the necessary skills or what the necessary tools are for that craft, which was also unique to Craftster. Overall, Craftster is not a good source for easily personalize able designs, nor designs that helped people with disabilities, but us good at fostering relationships between users and bridging the competence gaps in skills to engage in crafting.

\section{Instructables}

Instructables was chosen because it is an extremely broad DIY/Maker online community, in terms of the products, technology, and materials that it covers, as well as because of its explicit focus on tutorial creation. Users can find an astonishingly large selection of designs and products, split into many categories, including one specifically for assistive technology. This broadness allows Instructables to have an extremely diverse audience in terms of technical skills and experiences. Furthermore, Instructables is explicitly focused on the tutorial aspect of DIY/Making; it has an excellent embedded tutorial editor, which simplifies and standardizes tutorial authorship. Improving the knowledge transfer system (i.e the documentation and publishing process of tutorials) has been argued to be an important step in further increasing the accessibility of DIY/Maker online communities (Kuznetsov \& Paulos, 2010; Tseng \& Resnick, 
2014). To further this point, the ability to access and create an Instructable with a mobile device, via the mobile app, is another way that increases the accessibility of Instructables.

Although Instructables does have such a large scope, it does not have a freely accessible and dedicated section for learning requisite skills or how to use necessary tools. Instead Instructables depends mainly on users actually creating tutorials for certain skills like soldering or answering questions asked in the Forum and Answers sections, which is still helpful, if not the most organized. They do offer classes that teach the basics in topics like 3-D printing, electronics, and laser cutting, which require payment in the form of a one time fee or a paid Premium membership. For those willing and/or able to pay it seems that it would be a helpful way to learn from an expert in a professionally designed course format, however it is clearly less accessible than the typically open-access nature of most DIY/Maker online social communities.

One more feature that has the possibility of increasing user-initiated design is found in Instructables' forum section, specifically the message boards for offering services and requesting a design or product. While the success of those individual threads is entirely out of Instructables control, having a dedicated area for users to enlist the services of others, which brings together experienced and/or professional designers with users who may need assistance with the technical aspects of design, is one of the proposed improvements that Hook et al. (2014) suggested. Finding users interested in helping with a design, in conjunction with the ability for users to add collaborators to help co-author the tutorial, which is embedded in the tutorial editor, can directly encourage collaboration. Once added, collaborators can work with the original author to help write and modify the design. When considering UID for disabled 
people, this can be a great benefit in maintaining the design focus on the disabled individual while having the technical support of an experienced co-author.

While not the main focus of Instructables, they do recognize the applicability of their DIY/Maker online community in supporting disabled people via the assistive technology section. While some of the assistive technology designs were created by/for people with disabilities, non-disabled users are still the main contributors. Furthermore, it is difficult to ascertain disability among the Instructables users unless they self-identify as disabled in their personal profiles, or mention in the tutorial description that the product is meant to address their own disability or the disability of someone they personally know. This makes determining if UID actually occurred very contingent on non-compulsory information from the user. Overall, Instructables has a great emphasis on good tutorial authorship and the encouragement of collaboration and sharing of advice and information, but does not adequately provide free

resources for users wanting to learn about basic skills and tools. Furthermore, the recognition of Instructables as a place for disabled users to find and share designs, and potentially collaborating with more experienced designers, provides at least a starting point for centering UID for disabled users within Instructables.

\section{Thingiverse}

Thingiverse was chosen because it represented a very niche DIY/Maker online community that specializes in one type of DIY/Making tool, the 3-D printer. Although the breadth of materials and products in Thingiverse is nowhere near Instructables, the exclusive focus on 3-D printing allows Thingiverse to greatly standardize the resources and tutorials within the website. This makes it especially easy for users to copy and modify one another's design, made even easier by Thingiverse's embedded 3-D modelling app, Customizer, or one of 
the other free apps available for download from Thingiverse. Users can directly download the ready to be modified 3-D design files and re-upload their own take on it, with the attribution to the original designer maintained. This is another example of improving the tutorial authorship process by "seamlessly integrating designing and documenting" (Tseng \& Resnick, 2014, p. 428). However, the ability to actively collaborate with other users is relegated to remixing other users' designs rather than working on the same design together, as seen in Instructables.

Furthermore, while 3-D printing and modelling is still a hard process to learn, users require fewer resources to learn how to use Thingiverse because the bulk of the skills to DIY/Make with Thingiverse are limited to just 3-D modelling software. When compared to Craftster and Instructables, with their broad range of tools for the broad range of design mediums from different crafts/fields, users using Thingiverse have less technical skills to learn. The encompassing and free resources, under the sections of Jumpstart and Thingiversity, offered by Thingiverse include several tutorials that teach new users how to use different 3-D modelling apps. This should makes the competency gap smaller, both by providing the resources needed to learn as well as ensuring that the required skills are few in number. The 3D modeeling apps include Thingiverse's Customizer and Tinkercad, with certain apps meant for within browser use, others are computers programs meant for out of browser use, and one is even meant for tablet use. By harnessing multiple ways to create 3-D designs, on different device as well, the accessibility of DIY/Making further increases.

In regards to disability representation or emphasis in Thingiverse, it is very similar to Instructables. There is an assistive technology group created by users, although there are not very many designs in the group. Similarly, there are predominately non-disabled designers creating assistive devices, and whether or not the user is disabled is not particularly advertised. 
Users have to self-identify as disabled or mention it in the tutorial description, making it difficult to confirm if UID is being practiced.

\section{Presence of Disability in UID}

Generally, all three DIY/Maker online communities had the basic requirements for UID: the open and free sharing of designs/tutorials, the ability to learn from and modify other users' designs, and anyone technically being able to DIY/Make (access to materials, tools, and skills aside). However, their emphasis on promoting UID in the context of disability and disabled user participation was more variable. While Craftster had understandably minimal reference to disability as a main concern for those engaging in crafts, Instructables and Thingiverse at least partially acknowledged their applicability for UID specifically for disabled people. However, neither online community emphasizes the central importance of disabled designers engaging in DIY/Making for themselves.

Users not personally affected by or connected to disability are still creating the majority of assistive designs. Or at least that is what most user profiles and descriptions of tutorials are indicating. The number of users who are disabled and indicate so publicly is very small. Perhaps users are not self-identifying their personal connection to disability in the interest of privacy or because they perceive their personal disability to lack any relevance to the design itself. Regardless, disability is not central to these DIY/Maker online communities. This in itself may be one of the biggest unexplored barriers to disabled participation in DIY/Maker online communities.

As Shildrick (2009) argues, the active presentation of disability helps to disrupt the assumed able-bodied norm. Part of this assumption is that design can or should only be carried out by those considered part of the able-bodied norm, which must be challenged. Bringing the 
importance of disability to the forefront of these online communities may help users realize that their lived experience of disability is a strength when it comes to designing for themselves and other disabled people. This also points to another main issue with the DIY/Maker online communities; that of persistent ableism, where the users are assumed to have certain capabilities when it comes to physically conducting DIY/Making. The accessibility of DIY/Making itself is not seriously addressed in the above online communities, with the moderate exception for Thingiverse and its attempts at making 3-D printing more accessible via the multiple 3-D modelling apps across multiple devices. As Hurst and Kane (2013) suggest, the technology used to facilitate DIY/Making needs to become more accessible to users with disabilities. 3-D printing itself can remove some of the physical requirements of traditional design, like the use of power tools or manually taking precise measurements (Hurst \& Tobias, 2011). The accessibility of DIY/Making must nonetheless strive to improve, and the application of a critical disability lens to these online communities may prove to assist with that.

\section{Conclusion}

The purpose of this research paper was to first demonstrate the importance of UID for people with disabilities, and then to use the literature on disability, design, and DIY/Making to examine the features that support UID within current and popular DIY/Maker online communities. As traditional design practices have typically excluded the end-user from having input on the design process, spaces and products are often not as accessible or ideal for people with disabilities. While the intersection of design and disability have led to some improvements for disabled people, via the development of accessible and universal design, the user is still not the focus of the design process. UID seeks to truly put the user's goals and interests as the main focus for the design of the products they need. As UID is described above, it appears to be 
currently practiced in DIY/Maker online communities. However, due to the relatively new emergence of these online communities, there is little research evaluating their actual efficacy in supporting UID, specifically for people with disabilities. As a result this research paper sought to analyze these online communities for their strengths and weaknesses, and propose changes to improve their ability to encourage UID for disabled people.

In agreement with the literature, DIY/ Maker online communities need to ensure high quality tutorials, ensure that the competency gap among new DIY/Makers is bridged, and facilitate the collaboration between more experienced designers and novice designers. In addition, it seems that although the basic requirements for UID, such as the open access to designs and ability to learn from other users, are being met, the lack of disability emphasis or presence is problematic. UID has great potential to improve the lives of people with disabilities, but it must be implemented properly. Highlighting disability as strength in the design process is not common, and needs to be addressed in order to specifically increase disabled participation. This also pertains to the lack of consideration for the accessibility of the DIY/Maker online communities and tools for DIY/Making itself. New tools and ways of DIY/Making would help to address the physical barriers to UID. A new DIY/Maker online community that explicitly advocates for disabled people to design for themselves, where users openly discuss their own disabilities in connection with the designs they have created, while continuing to use the above features that support general UID, and striving for maximum accessibility is a lofty goal but one that may soon be reached. 


\section{References}

Allsop, M. J., Holt, H. J., Gallager, J. F., Leveley, M. C., \& Bhakta, B. (2010). The involvement of primary schools in the design of healthcare technology for children. In P. M. Langdon, P. J. Clarkson, \& P. Robinson. (Eds.). Designing Inclusive Interactions, (pp.209-218). London: Springer London.

Al-Zoabi, A. A strategic design of accessible buildings for people with a disability in Jordan. Architectural Science Review, 44(2), 181-186. doi:10.1080/00038628.2001.9697469

Andrade, I. F. \& Ely, V. H. M. B. (2012). Assessment method of accessibility conditions: How to make public buildings accessible. Work, 41(1), 3774-3780. doi:10.3233/WOR-2012$0675-3774$

Bates, M. J., \& Lu, S. (1997). An exploratory profile of personal home pages: Content, design, metaphors. Online and CD-ROM Review, 21(6), 331-340.

http://dx.doi.org/10.1108/eb024639

Bellucci, A., Di Santo, A., \& Nolan, J. (2016). Wild research: Unexpected opportunities, affordances and constraints doing AAC fieldwork in underserved areas. Manuscript submitted for publication.

Borg, J., \& Ostergren P.-O. (2015). Users' perspectives on the provision of assistive technologies in Bangaldesh: Awareness, provider, costs and barriers. Disability and Rehabilitation: Assistive Technology, 10(4), 301-308.

doi:10.3109/17483107.2014.974221

Buehler, E., Barnham, S., Ali, A., Chang, J. J., Hofmann, M. K., Hurst, A., \& Kane, S. K. (2015). Sharing is caring: Assistive technology on Thingiverse. CHI '15, Proceedings of 
the $33^{\text {rd }}$ Annual ACM Conference on Human Factors in Computing Systems, 525-534. doi:10.1145/2702123.2702525

Campbell, F. K. (2009). Contour of ableism: Territories, objects, disability and desire. London: Palgrave Macmillan.

Copley, J., \& Ziviana, J. (2004). Barriers to the use of assistive technology for children with multiple disabilities. Occupational Therapy International, 11(4), 229-243. doi:10.1002/oti.213

Craftster. (n.d.-a). Homepage. Retrieved from www.craftster.org

Craftster. (n.d.-b). City Guides for Crafsters. Retrieved from http://www.craftster.org/forum/index.php?board=369.0

Craftster. (n.d.-c). Crochet: Discussions and questions. Retrieved from http://www.craftster.org/forum/index.php?board=79.0

Craftster. (n.d.-d). The Craftster need to know guide. Retrieved from http://www.craftster.org/craftsterguide.html

Davidson, M. (2016). Cripping consensus: Disability studies at the intersection. American Literary History, 28(2), 433-453. doi:10.1093/alh/ajw008

Dalton, M. A., Desjardins, A., \& Wakkary, R. (2014). From DIY tutorials to DIY recipes. CHI '14: Proceedings of the 2014 CHI Conference Extended Abstracts on Human Factors in Computing Systems, 1405-1410. doi:10.1145/2559206.2581238

Entner, R. (2011, June 23). International comparisons: The handset replacement cycle. Mobile Future. Retrieved from http://mobilefuture.org/wp-content/uploads/2013/02/mobilefuture.publications.handset-replacement-cycle.pdf 
Ewaskiw, J. (2011, September 7). Internet Brands acquires smart design blog Inhabitat. Market Wired, Retrieved from http://www.marketwired.com/press-release/internet-brandsacquires-smart-design-blog-inhabitat-1558139.htm

Federici, S., \& Borsci, S. (2014). Providing assistive technology in Italy: The perceived delivery process quality as affecting abandonment. Disability and Rehabilitation Assistive Technology, 11(1), 22-31. doi:10.3109/17483107.2014.930191

FreakieGeekie. (2015, September 30). Devilishly simply costume (with horns pattern) [Msg 1]. Message posted to http://www.craftster.org/forum/index.php?topic=440902.0

Giacomen, J. (2015). What is human centered design? The Design Journal, 17(4), 606-623. doi:10.2752/175630614X140561854680186

Goodley, D. (2013). Dis/entangling critical disability studies. Disability \& Society, 28(5), 631644. http://dx.doi.org/10.1080/09687599.2012.717884

Goodley, D., \& Runswick-Cole, K. (2013). The body as disability and possibility: theorizing the 'leaking, lacking and excessive' bodies of disabled children. Scandinavian Journal of Disability Research, 15(1), 1-19. http://dx.doi.org/10.1080/15017419.2011.640410

Herring, S. C. (2010). Web content analysis: Expanding the paradigm. In J. Hunsinger, L. Klastrup, \& M. M. Allen (Eds.). International Handbook of Internet Research, (pp. 233249). London: Springer

Hook, J., Verbaan, S., Wright, P., \& Olivier, P. (2013). Exploring the design of technologies and services that support do-it-yourself assistive technology practice. Proceedings of $D E$ '13: The Fourth Annual Digital Economy All Hands Conference. Retrieved from http://www.de2013.org 
Hook, J., Verbaan, S., Durrant, A., Olivier, P., \& Wright, P. (2014). A study of the challenges related to DIY assistive technology in the context of children with disabilities. DIS '14: Proceedings of the 2014 Conference on Designing Interactive Systems, 597-606. doi:10.1145/2598510.2598530

Hurley, D. (2014, December 24). Diabetes patients are hacking their way toward a bionic pancreas. Wired. Retrieved from http://www.wired.com/2014/12/diabetes-patientshacking-together-diy-bionic-pancreases/

Hurst, A., \& Kane, S. (2013). Making “making' accessible. IDC '13: Proceedings of the $12^{\text {th }}$ International Conference on Interaction Design and Children, 635-638. doi:10.1145/2485760.2485883

Hurst, A., \& Tobias, J. (2011). Empowering individuals with do-it-yourself assistive technology. ASSETS '11: Proceedings of the $13^{\text {th }}$ International ACM SIGACCESS Conference on Computers and Accessibility, 11-18. doi:10.1145/2049536.2049541 instructables. (2015, December 3). List of Instructables. Retrieved from http://www.instructables.com/member/instructables?show=INSTRUCTABLES

Instructables. (n.d.-a). Everything page. Retrieved from http://www.instructables.com/tag/typeid/

Instructables. (n.d.-b). Community forum. Retrieved from http://www.instructables.com/community Kalof, L., Dan, A., \& Deitz, T. (2008). Essentials of social research. UK: McGraw-Hill Education. 
Karlgren, K., Ramberg, R., \& Artman, H. (2016). Designing interaction: How do interaction design students address interaction? International Journal of Technology and Design Education, 26(3), 439-459. doi:10.1007/s10798-015-9314-3

Kim, I., \& Kuljis, J. (2010). Applying content analysis to web-based content. Journal of Computing and Information Technology, 18(4), 369-375. doi:10.2498/cit.1001924

Kuznetsov, S., \& Paulos, E. (2010). Rise of the expert amateur: DIY projects, communities, and cultures. NordiCHI '10 Proceedings of the $6^{\text {th }}$ Nordic Conference on Human-Computer Interaction: Extending Boundaries, 295-304. doi:10.1145/1868914.1868950

Labb, A., \& Neely, E. (2014). Making way for maker culture. EDUCAUSE Review, 49(2), 5859. Retrieved from https://er.educause.edu/ /media/files/article-downloads/erm1425.pdf Lindter, S. (2014). Hackerspaces and internet of things in China: How makers are reinventing industrial production, innovation, and the self. China Information, 28(2), 145-167. doi:10.1177/0920203X14529881

Mallin, S. S. V., \& de Carvalho, H. G. (2015). Assistive technology and user-centered design: Emotion as element for innovation. Procedia Manufacturing, 3(1), 5570-5578. doi:10.1016/j.promfg.2015.07.738

Malloy, R. P. (2008). Inclusion by design: Accessible housing and mobility impairment. Hastings Law Journal, 60(4), 699-749.

Margolin, V., \& Margolin, S. (2002). A "social model” of design: Issues of Practice and Research. Design Issues, 18(4), 24-30. doi:10.1162/074793602320827406 McMillan, S. J. (2000). The microscope and the moving target: The challenge of applying content analysis to the world wide bed. Journalism and Mass Communications Quarterly, 77(1), 80-98. doi:10.1177/107769900007700107 
MINIFACTURE. (2013, January 3). Adjustable bottle cap opener / cap wrench. Retrieved from http://www.thingiverse.com/thing:40131

Mota, S. C. M. F. (2014). Bits, atoms, and information sharing: New opportunities for participation (Doctoral dissertation). Retrieved from Academia.edu.

mountain g. (2015, August 11). Strong plastic samurai sword. Retrieved from http://www.instructables.com/id/strong-plastic-samurai-sword/

Nielsen, J. (2000, March 19). Why you only need to test with 5 users. Nielsen Norman Group. Retrieved from https://www.nngroup.com/articles/why-you-only-need-to-test-with-5users/

Nolan, J. (2016). Tuning spaces for autistic engagement through user-initiated design. Unpublished manuscript, Department of Early Childhood Studies, Ryerson University, Toronto, Canada.

Norman, D. A. (2002). The design of everyday things. New York: Basic Books.

Norman, D. A. (2013). The design of everyday things: Revised and expanded. New York: Basic Books.

O'Kane, A. (2016). DIY health and wellbeing: The hackers and makers outpacing manufacturers and researchers. Frontiers in Public Health, Conference Abstract: 2nd Behaviour Change Conference: Digital Health and Wellbeing. doi:10.3389/conf.FPUBH.2016.01.00080

O’Kane, A., Hurst, A., Niezen, G. Marquardt, N., Bird, J., \& Abowd, G. (2016). Advances in DIY health and wellbeing. CHI EA '16: Proceedings of the 2016 CHI Conference Extended Abstracts on Human Factors in Computing Systems, 3453-3460. http://dx.doi.org/10.1145/2851581.2856467 
Overstreet, M. (2013, Januaray 12). MakerBot changes the name of Thingiverse to MakerBot Thingiverse. Make. Retrieved from http://makezine.com/2013/01/12/makerbot-changesthe-name-of-thingiverse-to-makerbot-thingiverse/

Persson, H., Ahman, H., Yngling, A. A., \& Gulliksen, J. (2015). Universal design, inclusive design, accessible design, design for all: Different concepts-one goal? On the concept of accessibility-historical, methodological and philosophical aspects. Universal Access in the Information Society, 14(4), 505-526. doi: 10.1007/s10209-014-0358-z

Pfeil, U., Zaphiris, P., \& Ang, C. S. (2006). Cultural differences in collaborative authoring of Wikipedia. Journal of Computer-Mediated Communication, 12(1), 88-113. doi:10.1111/j.1083-6101.2006.00316.x

Phillips, B., \& Zhao, H. (1993). Predictors of assistive technology abandonment. Assistive Technology: The Official Journal of RESNA, 5 (1), 36-45. doi:10.1080/10400435.1993.10132205

Reaume, G. (2014). Understanding critical disability studies. Canadian Medical Association. Journal, 186(16), 1248-1249. http://dx.doi.org.ezproxy.lib.ryerson.ca/10.1503/cmaj.

Renda, G., Jackson, S., Kuys, B., \& Whitfield, T. W. A. (2015). The cutlery effect: Do designed products for people with disabilities stigmatise them? Disability and Rehabilitation: Assistive Technology. Advance online publication. doi:10.3109/17483107.2015.1042077

Robitaille, S. (2010). Illustrated guide to assistive technology and devices. New York: Demos Medical Publishing

Sarmiento-Pelayo, M. P. (2015). Co-design: A central approach to the inclusion of people with disabilities. Revista de la Facultad de Medicina, 63(1), 149-154. http://dx.doi.org/10.15446/revfacmed.v63n3sup.49345 
Shildrick, M. (2009). Dangerous discourses of disability, subjectivity and sexuality. London: Palgrave Macmillan.

Stangler, D., \& Maxwell, K. (2012). DIY producer society. Innovations: Technology, Governance, Globalization, 7(3), 3-10. doi:10.1162/INOV_a_00134

Stephandis, C. (2001). User interface for all: New perspectives into human-computer interaction. In C. Stephandis (Eds.), User Interfaces for All - Concepts, Methods, and Tools, (pp.3-17). Mahwah, NJ: Lawrence Erlbaum Associates.

Thingiverse. (n.d.-a). Homepage. Retrieved from http://www.thingiverse.com/

Thingiverse. (n.d.-b). Jumpstart. Retrieved from http://www.thingiverse.com/jumpstart

Thomas, C. (2007). Sociologies of disability and illness: Contested ideas in disability studies and medical sociology. Basingstoke: Palgrave Macmillan.

Tseng, T., \& Resnick, M. (2014). Product versus process: Representing and appropriating DIY projects online. DIS '14: Proceedings of the 2014 Conference on Designing Interactive Systems, 425-428. doi:10.1145/2598510.2598540

Wakkary, R., Schilling, M. L., Dalton, M. A., Hauser, S., Desjardins, A., Zhang, X., \& Lin, H. W. J. (2015). Tutorial authorship and hybrid designers: The joy (and frustration) of DIY tutorials. CHI '15 Proceedings of the 33rd Annual ACM Conference on Human Factors in Computing Systems, 609-618. http://dx.doi.org/10.1145/2702123.2702550

Walsh, J., Roberts, R., Morris, R., \& Heinemann, L. (2015). Device connectivity: The next big wave in diabetes. Journal of Diabetes Science and Technology, 9(3), 701-705. doi:10.1177/1932296814568806 
Wauters, R. (2011, August 1). Autodesk acquires DIY community Instructables. TechCrunch. Retrieved from https://techcrunch.com/2011/08/01/autodesk-acquires-diy-communityinstructables/

West, J., \& Kuk, G. (2016). The complementarity of openness: How MakerBot leveraged Thingiverse in 3D printing. Technological Forecasting \& Social Change, 102, 169-181. http://dx.doi.org/10.1016/j.techfore.2015.07.025

Williams, A., Gibb, A., \& Weekly, D. (2012). Research with a hacker ethos: What DIY means for tangible interaction research. Interactions, 19(2), 14-19. doi:10.1145/2090150.2090156

Williamson, T., Kenney, L., Barker, A. T., Cooper, G., Good, T., Healey, J., ... Smith, C. (2015). Enhancing public involvement in assistive technology design research. Disability and Rehabilitation Assistive Technology, 10(3), 258-265.

doi:10.3109/17483107.2014.908247 